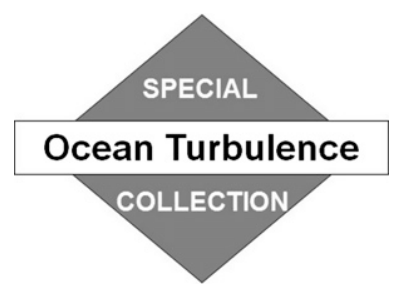

\title{
On the Circulation of Atlantic Water in the Arctic Ocean
}

\author{
Michael A. Spall \\ Woods Hole Oceanographic Institution, Woods Hole, Massachusetts
}

(Manuscript received 9 April 2013, in final form 6 August 2013)

\begin{abstract}
An idealized eddy-resolving numerical model and an analytic three-layer model are used to develop ideas about what controls the circulation of Atlantic Water in the Arctic Ocean. The numerical model is forced with a surface heat flux, uniform winds, and a source of low-salinity water near the surface around the perimeter of an Arctic basin. Despite this idealized configuration, the model is able to reproduce many general aspects of the Arctic Ocean circulation and hydrography, including exchange through Fram Strait, circulation of Atlantic Water, a halocline, ice cover and transport, surface heat flux, and a Beaufort Gyre. The analytic model depends on a nondimensional number, and provides theoretical estimates of the halocline depth, stratification, freshwater content, and baroclinic shear in the boundary current. An empirical relationship between freshwater content and sea surface height allows for a prediction of the transport of Atlantic Water in the cyclonic boundary current. Parameters typical of the Arctic Ocean produce a cyclonic boundary current of Atlantic Water of $O\left(1-2 \mathrm{~Sv}\right.$; where $\left.1 \mathrm{~Sv} \equiv 10^{6} \mathrm{~m}^{3} \mathrm{~s}^{-1}\right)$ and a halocline depth of $O(200 \mathrm{~m})$, in reasonable agreement with observations. The theory compares well with a series of numerical model calculations in which mixing and environmental parameters are varied, thus lending credibility to the dynamics of the analytic model. In these models, lateral eddy fluxes from the boundary and vertical diffusion in the interior are important drivers of the halocline and the circulation of Atlantic Water in the Arctic Ocean.
\end{abstract}

\section{Introduction}

The Arctic Ocean plays an important role in the global climate system through its absorption/reflection of solar radiation (which is strongly dependent on the presence of sea ice), as a conduit for freshwater input from rivers, and through water mass modification by exporting both fresh buoyant surface waters and dense salty deep waters. The Arctic Ocean is a semienclosed marginal sea that is connected to the lower-latitude oceans through several shallow and/or narrow passages. It is connected to the Nordic seas through the Fram Strait, which is relatively narrow and deep $(2600 \mathrm{~m})$, and the shallower Barents Sea (200-300 m). The exchange through the upper $1000 \mathrm{~m}$ of Fram Strait is dominated by an inflow of warm and salty Atlantic Water and an export of cold freshwater near the surface and dense salty water at depth.

There is a large freshwater input to the Arctic Ocean through river runoff and precipitation. The water entering

Corresponding author address: Michael Spall, MS \#21, 360 Woods Hole Road, Woods Hole, MA 02543.

E-mail:mspall@whoi.edu through Bering Strait is generally fresher than the inflowing Atlantic Water so, relative to that salinity, the Pacific inflow is also a source of freshwater. Because of this, the surface waters over the shelves in the Arctic are much fresher than the Atlantic water entering through Fram Strait. This buoyant water of shelf origin is carried into the interior near the surface, leading to the salinitydominated stable stratification and the halocline. The processes by which this freshwater is transported to the basin interior are not well known, but it is thought that both baroclinic eddies (e.g., Manley and Hunkins 1985) and wind forcing (e.g., Pickart et al. 2013) may be important. This stable stratification allows the surface waters to become very cold and for ice to form. This provides an effective barrier to strong exchange between the waters below the upper halocline and the atmosphere, although there is a net heat loss of $O\left(2-10 \mathrm{~W} \mathrm{~m}^{-2}\right)$ from the ocean to the ice (e.g., Maykut 1982; Krishfield and Perovich 2005). This is much less heat loss than is found over the warmer, ice-free waters in the Nordic seas, which is $O\left(50 \mathrm{~W} \mathrm{~m}^{-2}\right)$ (Isachsen et al. 2007).

Two of the most prominent features of the Arctic Ocean are the halocline and the circulation of Atlantic Water. 


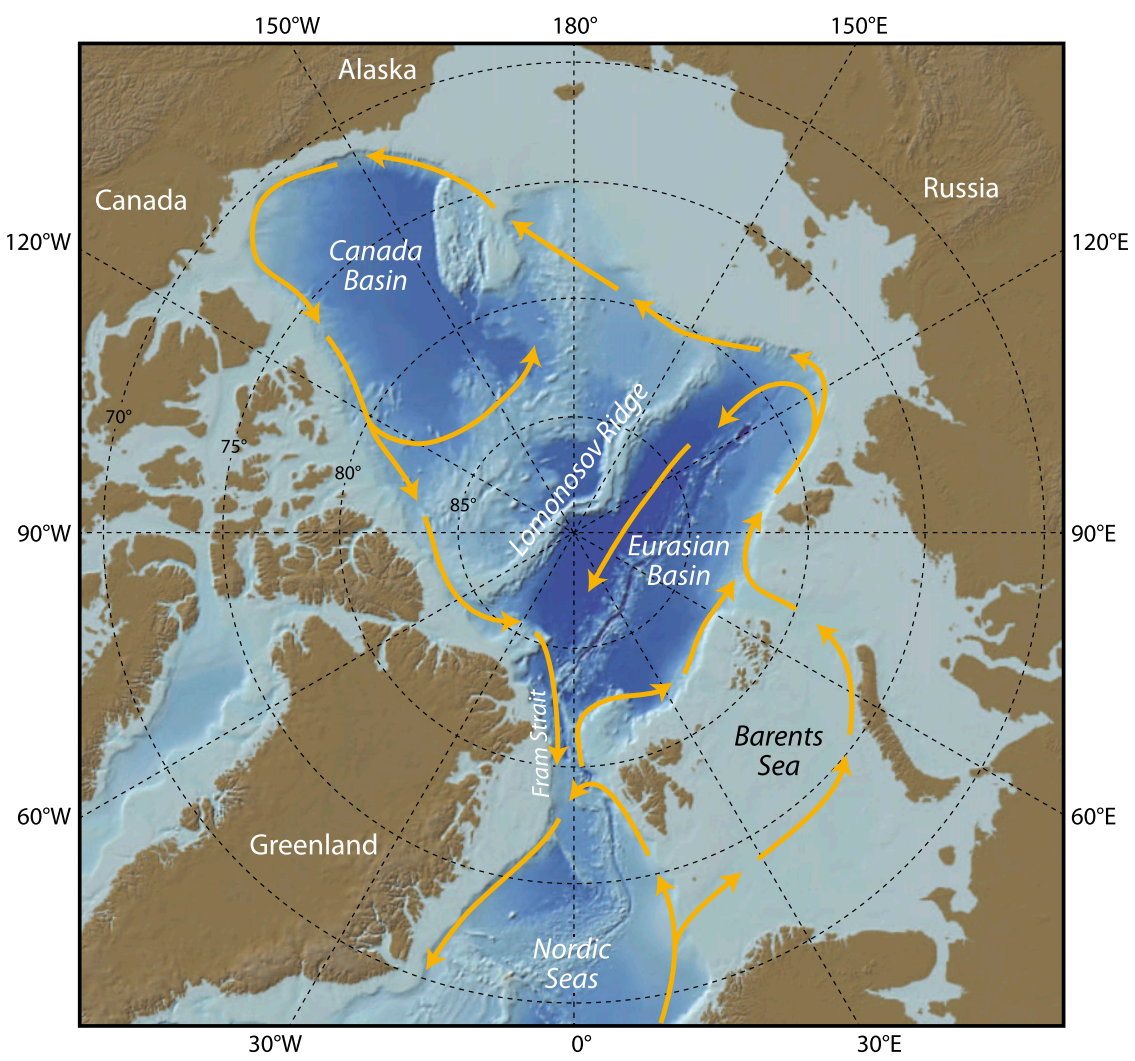

FIG. 1. Bottom topography and schematic of the Atlantic Water circulation in the Arctic Basin [modified from Rudels et al. (1994) and Rudels (2012)].

The Atlantic Water splits into three main branches in the northern Nordic seas [Fig. 1, adapted from Rudels et al. (1994) and Rudels (2012)]. One branch recirculates south of, or just to the north of, Fram Strait. The two remaining inflows through Fram Strait and the Barents Sea merge near the Barents Sea outflow and continue cyclonically around the Eurasian Basin. Part of this transport separates from the boundary near the Lomonosov and Nansen-Gakkel Ridges and flows back toward Fram Strait, while the remainder continues cyclonically around the Eurasian Basin and into the Canada Basin (Rudels et al. 1994; Aksenov et al. 2011). The transports in each of these branches are not well known, but sparse mooring measurements by Woodgate et al. (2001) estimate the boundary current transport approaching the ridge from the east to be $5 \pm 1 \mathrm{~Sv}$ (where $1 \mathrm{~Sv} \equiv 10^{6} \mathrm{~m}^{3} \mathrm{~s}^{-1}$ ), with $3 \pm$ 1 Sv turning back toward Fram Strait along the Lomonosov Ridge and another $3 \pm 1 \mathrm{~Sv}$ found to the west of the ridge in the cyclonic boundary current.

The complexities of the Arctic Ocean, including ice freezing and melting, shelf-basin exchange, the combined importance of salinity and temperature, and the range of possibly important forcing mechanisms, have made it difficult to develop a simple, conceptual model that describes the dominant features of the Arctic Ocean and relates them to the basic forcing parameters. Comprehensive models suggest that all of wind, heat, freshwater forcing, and the seasonal cycle are important; however, even these complicated models do not always produce consistent basic circulation patterns (Proshutinsky et al. 2011; Karcher et al. 2007; Holloway et al. 2007). The goal of the present study is to develop a simple, minimal model of the Arctic Ocean that is able to reproduce two prominent elements of the region-the halocline and the circulation of Atlantic Water-and to understand how these depend on the basic parameters of the system.

\section{An idealized numerical model of the Arctic Ocean}

\section{a. Model configuration}

The basic problem of the Arctic Ocean circulation is first considered using an eddy-resolving configuration of the Massachusetts Institute of Technology (MIT) primitive equation general circulation model (MITgcm; Marshall et al. 1997). The model domain consists of three basins: a southern reservoir of warm, salty water (the North Atlantic); a northern semienclosed basin (the Arctic Ocean); and a basin that connects these two (the 


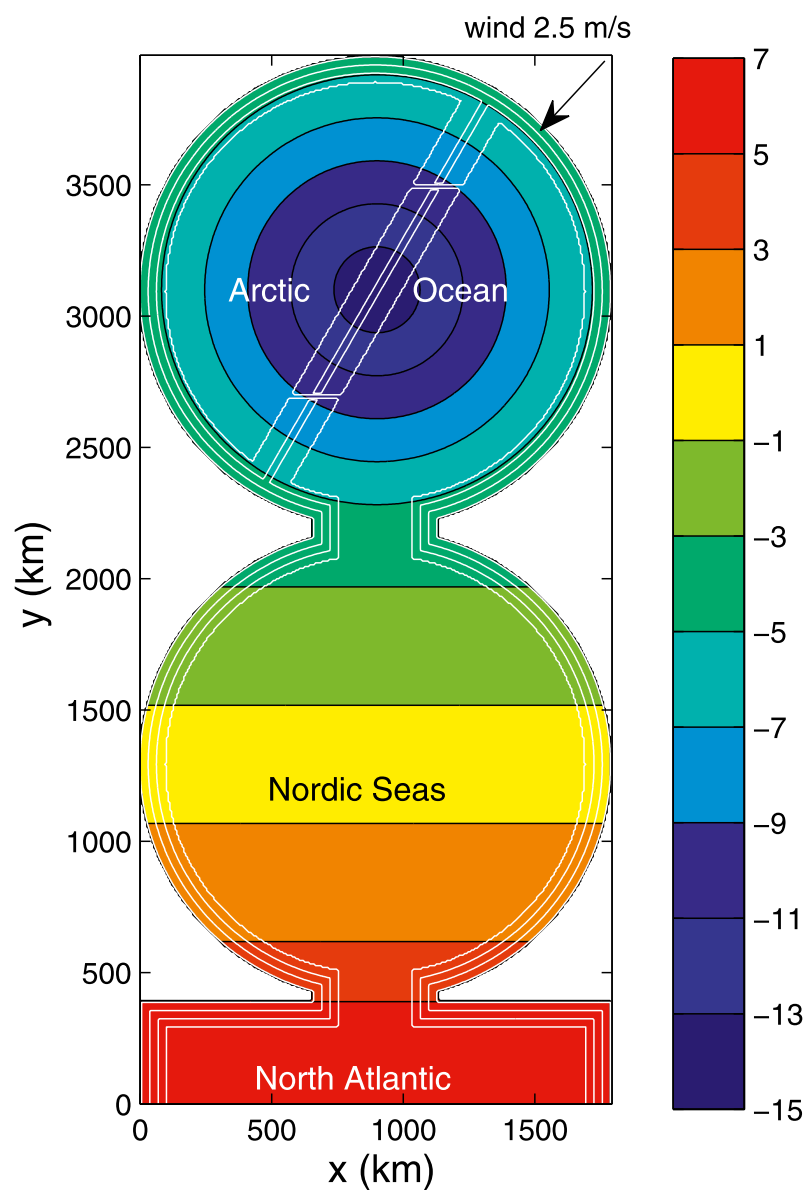

FIG. 2. The model domain and forcing. Atmospheric temperature is indicated by the colors $\left({ }^{\circ} \mathrm{C}\right)$, bottom topography by the white contours (250-m contour interval). There is a uniformly sloping region $100-\mathrm{km}$ wide around the basin perimeter and a ridge $300-\mathrm{m}$ tall in the Arctic Basin that is perforated by two gaps. The wind speed is uniform at $2.5 \mathrm{~m} \mathrm{~s}^{-1}$ and directed as indicated by the vector in the upper right corner of the figure. To the south of $y=350 \mathrm{~km}$, the model temperature and salinity are restored toward $6^{\circ} \mathrm{C}$ and 35 , respectively.

Nordic seas) (Fig. 2). Although the model is clearly very idealized, and not intended to represent the real world in any detailed manner, names based on the real geography will be used to describe the model configuration and in discussion of the results. The maximum bottom depth is $1000 \mathrm{~m}$, with a $100-\mathrm{km}$-wide region of sloping topography around the basin perimeter. The actual Arctic Ocean is much deeper than $1000 \mathrm{~m}$, but the main focus of this study in on the circulation in the Atlantic layer (shallower than $1000 \mathrm{~m}$ ) and development of the halocline. There is a 300-m-tall ridge that separates the Arctic Basin into eastern and western subbasins, analogous to the Lomonosov Ridge and the Eurasian and Canada Basins.

The ocean circulation model is coupled to an ice model with thermodynamics that simulate ice thickness and concentration, based on the two-category model of
Hibler (1980). The albedo reflects that of wet (0.66) or dry (0.75) ice, depending on if there is sufficient heat flux to form melt pools. The two-category ice model uses a so-called zero-layer thermodynamic model to estimate ice growth and decay. The zero-layer thermodynamic model assumes that ice does not store heat. This is not an issue for the present application because there is no seasonal cycle. The ice model dynamics are elasticviscous-plastic (Hunke and Dukowicz 1997).

The model is forced by restoring the ocean surface temperature toward an atmospheric temperature with strength $30 \mathrm{~W} \mathrm{~m}^{-2}{ }^{\circ} \mathrm{C}^{-1}$. This is a rough approximation for the sensible and latent heat fluxes, which increase as the air-sea temperature difference increases. With the objective of keeping the model simple, short- and longwave radiation are ignored. The atmospheric temperature is shown in Fig. 2 by the colors. It is coldest in the middle of the Arctic Basin and warms toward the south (even though this is an $f$ plane, for the purpose of discussion north is toward the center of the Arctic Basin in the model). This air temperature is similar to the annualmean atmospheric temperature at $10 \mathrm{~m}$ from the National Centers for Environmental Prediction (NCEP), although the general behavior is not sensitive to the details of the atmospheric temperature as long as it is sufficiently cold to form ice in the Arctic Basin. The model is also forced with a uniform wind speed of $2.5 \mathrm{~m} \mathrm{~s}^{-1}$ directed from the upper right to the lower left in Fig. 2. This wind speed and direction are similar to the annual-mean winds in the central Arctic. This wind is not realistic over the Nordic seas or the western Arctic Basin; however, a uniform wind is used here to demonstrate the circulation that results in the absence of any wind stress curl.

There is no precipitation or evaporation at the surface. Freshwater forcing is introduced by restoring the model salinity to a value $S_{1}=31$ over the upper thickness $h_{1}=50 \mathrm{~m}$ within $100 \mathrm{~km}$ of the outer boundary (over the sloping bottom) in the Arctic Ocean for $y>$ $2350 \mathrm{~km}$. This is intended to represent the processes that transport freshwater from the shelf, which is provided by river runoff and transport through Bering Strait, across the shelf break. The dynamics that control this exchange likely occur on very small scales that would be difficult to resolve in a basin-scale model and on high-frequency atmospheric forcing, which is not represented in this simple model. However, an advantage of this approach is that it also allows for direct control of the amount of freshwater near the coast in order to directly deduce its influence on the interior circulation and halocline (both salinity $S_{1}$ and thickness $h_{1}$ will be varied).

This cooling and freshening at high latitudes is balanced, in an integrated sense, by restoring the model temperature and salinity toward uniform values of $6^{\circ} \mathrm{C}$ and 
$S_{2}=35$ within the North Atlantic region $(y<350 \mathrm{~km})$ with a time scale of 30 days. This provides a source of warm, salty water and allows for equilibrium solutions to be attained. The mass flux out of this restoring region is not specified, but instead emerges as part of the solution. It is inherently assumed that mixing energy and external sources of salt and heat are available to maintain this source of water, independent of whatever happens in the active basins to the north. Similar restoring regions have been used by Spall $(2004,2011,2012)$.

The model is configured on an $f$ plane with constant rotation rate $f_{0}=1.2 \times 10^{-4} \mathrm{~s}^{-1}$. The horizontal grid spacing is $6.7 \mathrm{~km}$ and there are 30 levels in the vertical ( $25 \mathrm{~m}$ thick over the upper $500 \mathrm{~m}$ and $50 \mathrm{~m}$ thick over the lower $500 \mathrm{~m}$ ). The baroclinic deformation radius based on the salinity difference between the Atlantic Water $S_{2}=35$ and the fresh surface water $S_{1}=31\left(g^{\prime}=\right.$ $\left.0.03 \mathrm{~m} \mathrm{~s}^{-2}\right)$ and a layer thickness of freshwater near the boundary $\left(h_{1}=50 \mathrm{~m}\right)$ is $L_{d}=\left(g^{\prime} h_{1}\right)^{1 / 2} / f_{0}=10.4 \mathrm{~km}$, or about $50 \%$ larger than the grid spacing.

The model incorporates second-order vertical viscosity and diffusivity with coefficients $10^{-5} \mathrm{~m}^{2} \mathrm{~s}^{-1}$. The vertical diffusion is increased to $1000 \mathrm{~m}^{2} \mathrm{~s}^{-1}$ for statically unstable conditions in order to represent vertical convection. Quadratic bottom drag is applied with coefficient $10^{-3}$. Horizontal viscosity is parameterized as a second-order operator with the coefficient $A_{h}$ determined by a Smagorinsky closure (Smagorinsky 1963) as $A_{h}=\left(v_{s} / \pi\right)^{2} \delta X^{2}\left[\left(u_{x}-v_{y}\right)^{2}+\left(u_{y}+v_{x}\right)^{2}\right]^{1 / 2}$, where $v_{s}=2.5$ is a nondimensional coefficient, $\delta X$ is the grid spacing, and $u$ and $v$ are the horizontal velocities (subscripts indicate partial differentiation). For a typical mean boundary current velocity of $5 \mathrm{~cm} \mathrm{~s}^{-1}$ in the northern basin, this gives a lateral viscosity of approximately $10 \mathrm{~m}^{2} \mathrm{~s}^{-1}$. Temperature and salinity are advected with a third-order direct space-time flux-limiting scheme (MITgcm tracer advection option 33; http://mitgcm.org). There is no explicit horizontal diffusion of temperature or salinity. Density is calculated from temperature, salinity, and depth using the relation from Jackett and McDougall (1995).

This configuration and forcing are of course a gross simplification of the actual subpolar and polar seas, but their simplicity, and the reduced size of the basin compared to the real ocean, allows for higher resolution in the model and for systematic variations of parameters and simplified diagnostics of the model fields. In particular, this approach clearly separates the boundary region with sloping bottom topography from the flat interior. As will be discussed below, these two regions are dynamically distinct and the interaction between the two provides the key framework with which to understand the model results. The simplified atmospheric forcing also allows us to retain what appear to be the minimal components that produce the primary elements of the Arctic Ocean and Atlantic Water circulation. Additional forcing mechanisms not considered here, such as wind stress curl, a seasonal cycle, precipitation and evaporation, long- and shortwave radiation, and low-frequency variability, are surely important for many aspects of the Arctic hydrography and circulation, but perhaps not necessary for the basic existence of the halocline and circulation of Atlantic Water.

The model is initialized at rest and run for a period of 100 years. The initial temperature field is uniform at $-1.95^{\circ} \mathrm{C}$, approximately the freezing point of water, although there is initially no sea ice. The initial salinity field is 35 everywhere except in the upper $100 \mathrm{~m}$ within the Arctic Basin, where it is 31 . This provides an initial halocline in the Arctic, although a calculation initialized with salinity 35 everywhere produces essentially the same results. The upper ocean equilibrates in 30-40 years, while the deep ocean (below $700 \mathrm{~m}$ ) is still slowly warming after 100 years. The quantities diagnosed below (halocline depth, surface salinity, ice thickness, and surface heat flux) do not vary significantly after 50 years of integration, although the transport of Atlantic Water in the cyclonic boundary current decreased by $15 \%$ between years 50 and 100 , so there is some drift remaining in the system.

\section{b. Model results}

The mean circulation and hydrography of the above model calculation are first described and compared with observations from the Arctic Ocean. The temperature, horizontal velocity (every 10th grid point), and salinity at $162.5-\mathrm{m}$ depth, averaged over the final 20 years of integration, are shown in Fig. 3 for the northern Nordic seas and Arctic Basin. This depth, near the base of the halocline and top of the Atlantic Water, was chosen to indicate the general circulation pattern within each layer. The vertical structure is indicated in the vertical sections discussed later in the paper. A cyclonic circulation develops in the Nordic seas, with warm, salty water flowing northward along the eastern boundary and colder, fresher water flowing southward in the western basin (only the northern part of the Nordic seas is shown here). Some of the warm water recirculates to the south of the model Fram Strait, and some (approximately $6 \mathrm{~Sv}$ ) flows into the model Arctic Basin. Within the Arctic Basin, there is a cyclonic boundary current of relatively warm and salty water. The transport in this boundary current around the western basin is approximately $2 \mathrm{~Sv}$. There is also an anticyclonic circulation of $O(5 \mathrm{~Sv})$ of colder, fresher water in the interior, most evident in the basin to the west of the ridge. This freshwater is seen flowing over the northern gap in the ridge into the eastern 

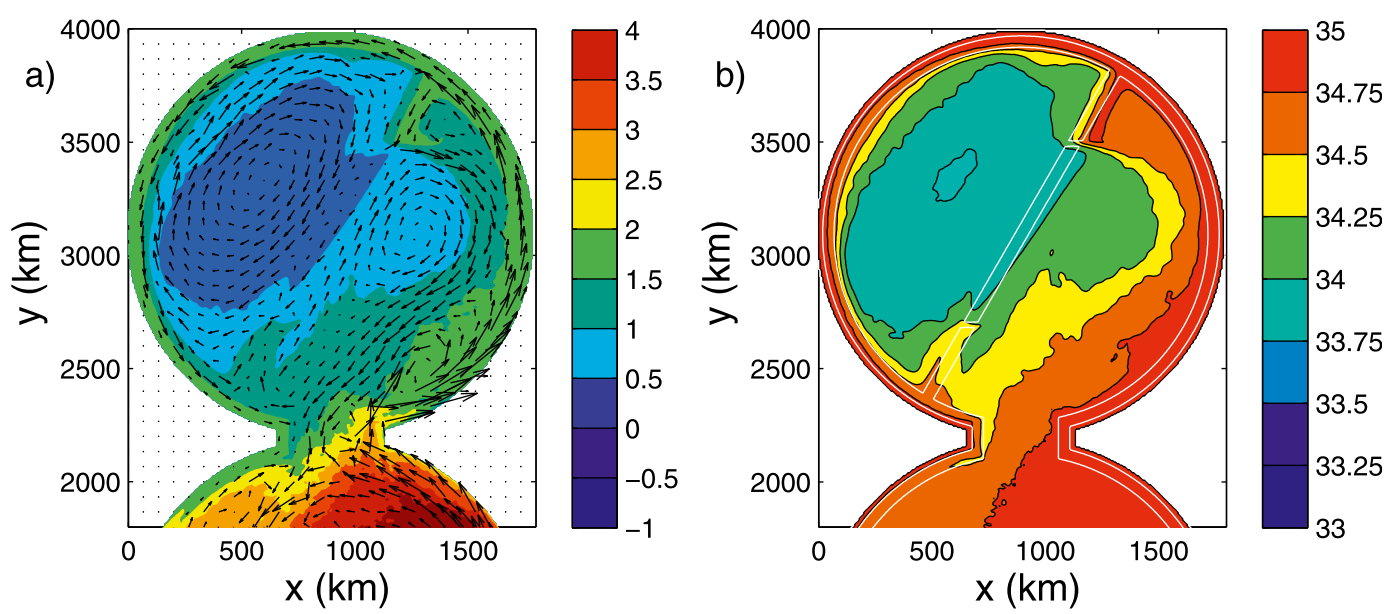

FIG. 3. Mean (a) temperature $\left({ }^{\circ} \mathrm{C}\right)$ and horizontal velocity (every 10 th grid point) and (b) salinity at $162.5-\mathrm{m}$ depth.

half of the Arctic Basin, leading to a weaker anticyclonic circulation there. It is somewhat surprising that the model produces such an anticyclonic circulation given that the observed anticyclonic circulation of the Beaufort Gyre is commonly thought to be driven by the anticyclonic wind stress curl (Proshutinsky et al. 2009). The anticyclonic circulation in the model is driven primarily by anticyclonic ice stress curl driven by the gradient in ice velocity across the western basin (Fig. 5, described in greater detail below). Much of the water that flows into the Arctic Basin leaves the eastern boundary downstream of the inflow and recirculates through the eastern part of the Arctic Basin and flows back into the Nordic seas. Similar flow patterns are found at deeper depths, although the temperature and salinity are much more homogeneous. Thus, the model produces three main circulation pathways for the Atlantic Water: one that recirculates to the south of Fram Strait $(\approx 7 \mathrm{~Sv})$; one that recirculates in the eastern Arctic Basin $(\approx 4 \mathrm{~Sv})$; and one that flows in a cyclonic boundary current around the $\operatorname{Arctic} \operatorname{Basin}(\approx 2 \mathrm{~Sv})$. These circulation pathways agree, in a general way, with the dominant circulation of Atlantic Water described by Rudels et al. (2008), Fig. 1.

The mean exchange through the model Fram Strait is dominated by a nearly barotropic inflow of warm, salty Atlantic Water and a barotropic outflow of slightly cooler, salty water and a strongly baroclinic outflow of cold, freshwater near the surface (Fig. 4), consistent with the observed inflow in the upper $800 \mathrm{~m}$. The mean northward transport through the strait is $5.6 \mathrm{~Sv}$. This is similar to, but somewhat smaller than, directly measured northward transports through the strait of $7-8 \mathrm{~Sv}$ (Marnela et al. 2012). Other estimates place the northward transport closer to $10 \mathrm{~Sv}$ (Fieg et al. 2010). The net liquid freshwater flux through the model strait (relative to $34.92)$ is $63 \mathrm{mSv}$. This compares well with observational estimates of $65 \mathrm{mSv}$ (Rudels et al. 2008), $50-60 \mathrm{mSv}$ (Marnela et al. 2012), and $80 \mathrm{mSv}$ (Rabe et al. 2009). The net transport per unit depth through the strait (Fig. 4d) shows that the Arctic Basin in the model acts largely as an estuary with a net inflow of dense water and a net outflow of lighter (fresher) water. There is also a net outflow at depths below $600 \mathrm{~m}$ at lower temperature than the inflowing water. Such a double estuary driven by freshwater input and cooling has been the basis of previous conceptual models of the Arctic by Stigebrandt (1981) and Rudels (1989).

Because the model is in steady state, the exchange through the model Fram Strait is consistent with a basin integral of the potential vorticity budget and the flux through the strait. However, the inflow and outflow transport and potential vorticity are not specified through a lateral boundary condition, as in Yang (2005), rather the exchange is determined by the dynamics and buoyancy forcing within the basin. For a linear, two-layer buoyancydriven flow, information propagates along characteristics that are given by the bottom topography and are in the direction of topographic wave propagation (Spall 2005), into the basin on the right-hand side of Fram Strait and out of the basin on the left-hand side of the strait. In this case, the mixing within the basin determines the potential vorticity and location of the outflowing water on the lefthand side of the strait, the potential vorticity of the outflowing water does not determine the mixing within the basin. In the end, the same budget constraints are satisfied but the interpretation of cause and effect is opposite.

The mean sea ice thickness and ice velocity are shown in Fig. 5. The ice thickness varies from less than $1 \mathrm{~m}$ on the eastern side of the basin to approximately $5 \mathrm{~m}$ on the western side of the basin. The pattern is generally dominated by advection from the wind. The sea ice is advected through the Fram Strait with speeds of $O\left(10 \mathrm{~cm} \mathrm{~s}^{-1}\right)$. 

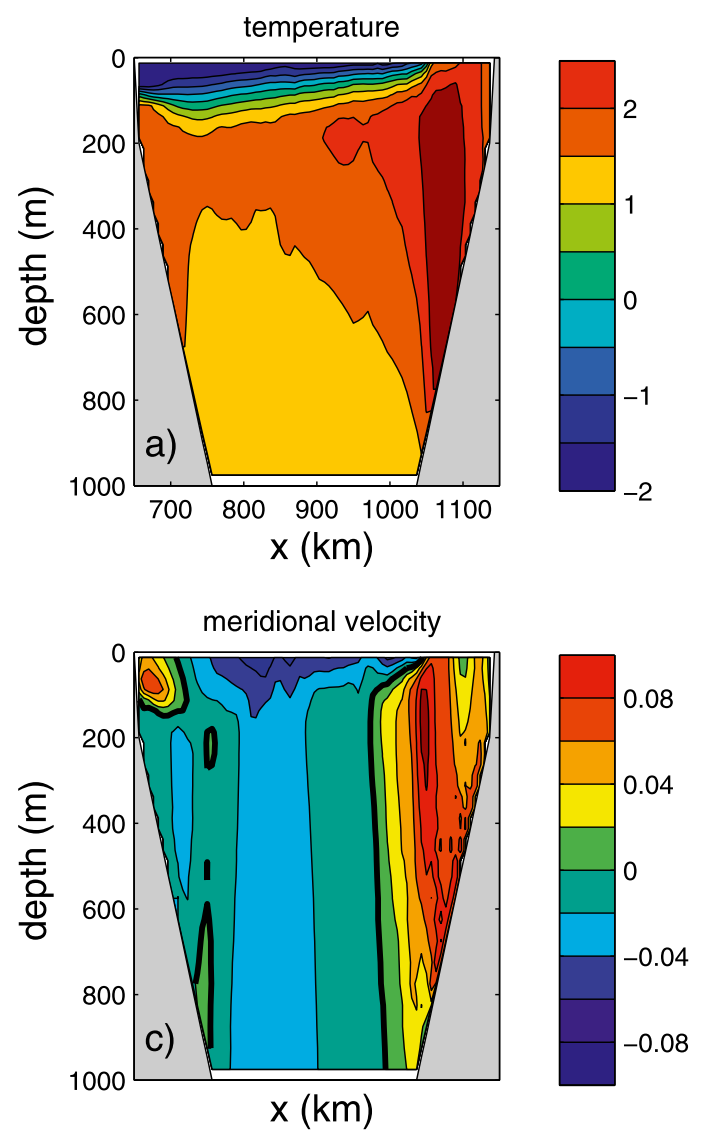
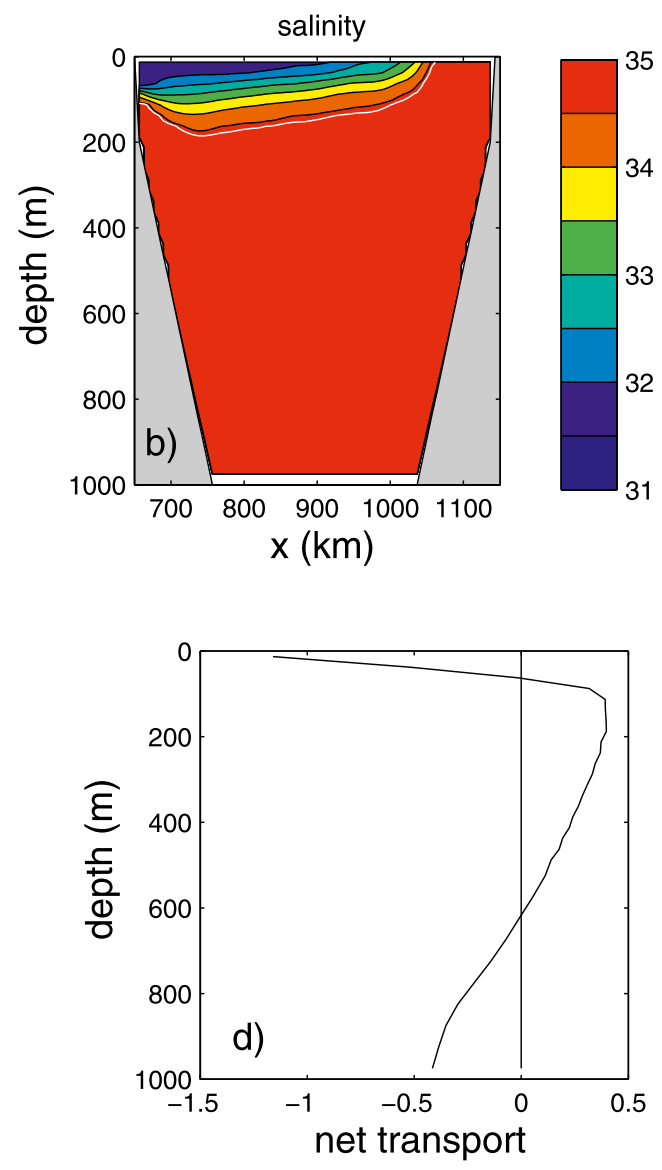

FIG. 4. Mean sections at $y=2200 \mathrm{~km}$ (model Fram Strait). (a) Temperature $\left({ }^{\circ} \mathrm{C}\right)$, (b) salinity, (c) meridional velocity $\left(\mathrm{m} \mathrm{s}^{-1}\right)$, and (d) net northward transport per unit depth $\left(10^{4} \mathrm{~m}^{2} \mathrm{~s}^{-1}\right)$.
There is also an anticyclonic circulation of sea ice of several centimeters per second in the western basin where the ice is actually moving into the wind. This general pattern and magnitude are consistent with the observations of Serreze and Barry (2005, p. 184), even though there is no wind stress curl in the model. In the present case, the stress imparted on the ocean by the southward-flowing ice is responsible for the anticyclonic curl and forcing of the anticyclonic circulation in the western basin.

The halocline is perhaps the most prominent feature of the Arctic hydrography. The model produces a strongly stratified, fresh surface layer that overlies the deep, weakly stratified warm and salty Atlantic Water. The depth of the model halocline, taken here to be the 34.6 salinity surface, is shown in Fig. 6a (vertical sections of salinity and temperature, clearly showing the halocline, will be discussed in the following section). It is approximately $285 \mathrm{~m}$ in the center of the western basin and less than $100 \mathrm{~m}$ around the basin perimeter. The influence of freshwater flowing from the western basin into the eastern basin over the northern ridge gap is evident and leads to a deepening of the halocline in the eastern basin. The halocline depth is very similar to the depth-integrated transport streamfunction in the basin interior (not shown). The recirculation of Atlantic Water in the eastern basin is driven by the strong gradient in upper ocean salinity in the basin interior. This gradient is provided by the contrast of halocline waters that originated in the western basin (fresh) and those that originated in the eastern basin (salty). Details of this transition, and the resulting geostrophic currents, depend on details of the ridge (gaps and height), but such a gradient and southward flow is always found in the model. Note the similarity between the salinity at $162.5 \mathrm{~m}$, the halocline depth, and the recirculation in the eastern Arctic Basin.

Another measure of the amount of freshwater in the upper ocean is the freshwater content, defined as the vertical integral of the salinity relative to $S_{r}=34.8$ down to the depth where $S=S_{r}$ or the bottom, whichever is less:

$$
F=\int_{0}^{H}\left(S_{r}-S\right) / S_{r} d z
$$




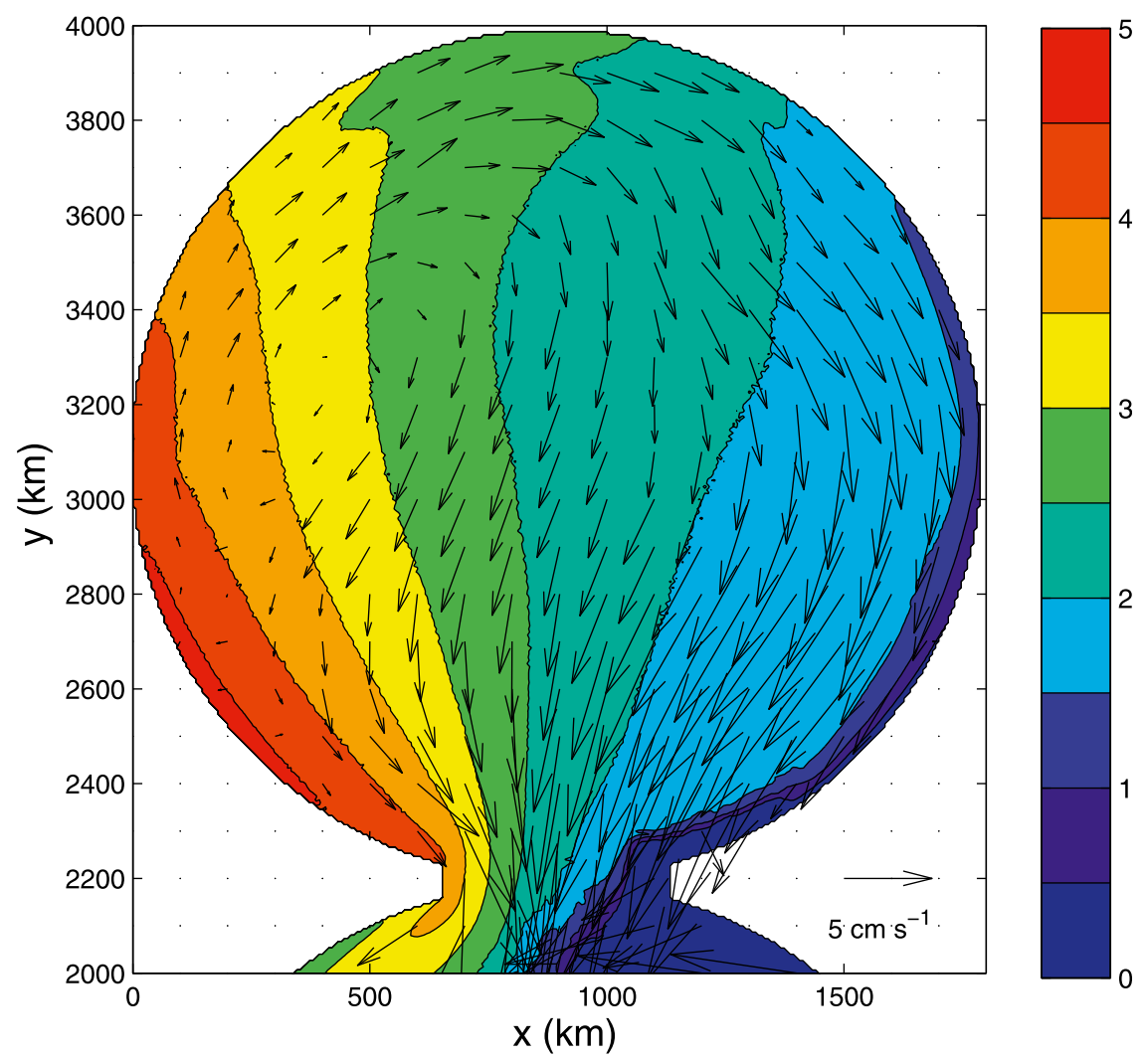

FIG. 5. Mean ice thickness (m) and velocity (every 15 th grid point).

The freshwater content is shown in Fig. 6b. It is striking how uniform the freshwater content is within the interior of the basin. It is approximately $10-11 \mathrm{~m}$ in the western basin and $9 \mathrm{~m}$ in the eastern basin. It is much more homogeneous than salinity or halocline depth. This is a consequence of no surface salinity forcing and no Ekman pumping, and is an indication that there is strong lateral stirring within the basin interior. Because the total salt content is nearly constant in the basin interior, vertical diffusion must be responsible for variations of halocline depth. The freshwater content is zero where the Atlantic Water flows into the basin and gradually increases cyclonically around the basin. This is partly a result of vertical diffusion bringing freshwater downward
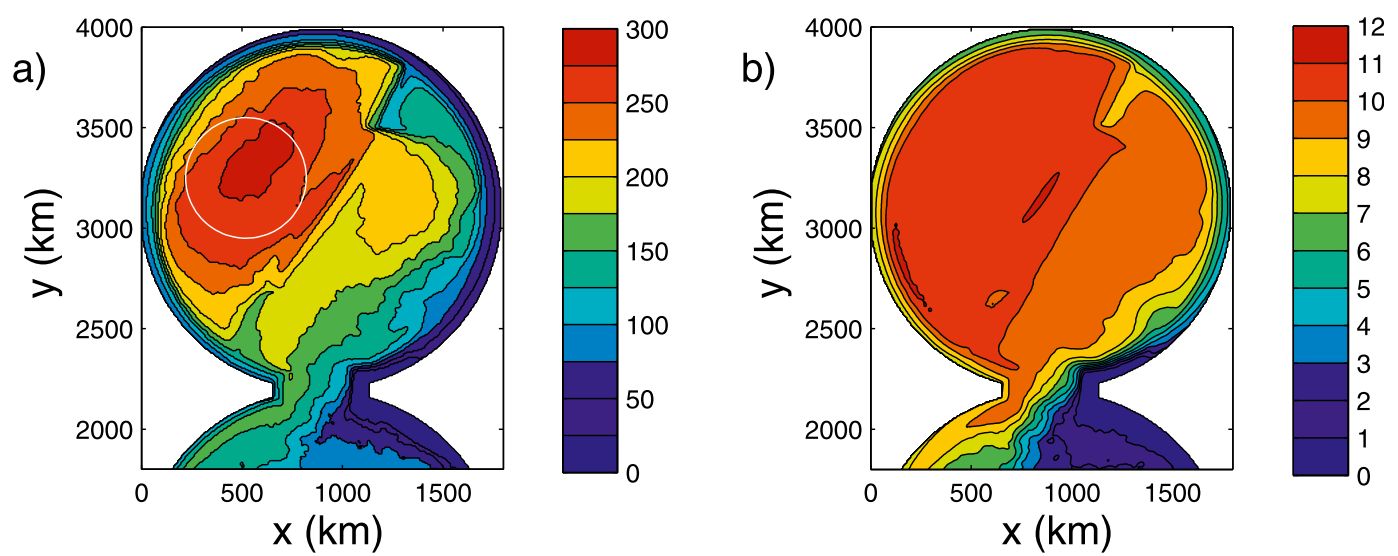

FIG. 6. Mean (a) depth of the halocline ( $\mathrm{m}$; defined as 34.6 salinity surface) and (b) freshwater content ( $\mathrm{m}$; relative to 34.8 ). The white contour in (a) is the region used to calculate the average halocline depth, surface salinity, freshwater content, and surface heat flux for comparison with the theory in section 3 . 
below the restoring region, which maintains low salinity in the upper $50 \mathrm{~m}$. The observed long term-mean freshwater content is $O(15 \mathrm{~m})$-somewhat larger than that found in the model, but still of similar order of magnitude (Proshutinsky et al. 2009). The observed maximum in the center of the Beaufort Gyre is not represented in the model, likely because of the lack of Ekman pumping driven by wind stress curl (the ice stress curl in the model is very weak).

Although the Atlantic Water is largely shielded from the atmosphere because of the halocline and ice, there is still a net heat flux from the ocean to the ice. The mean heat flux is shown in Fig. 7 (note the logarithm scale). The heat loss in the interior of the basin is generally $O\left(2 \mathrm{~W} \mathrm{~m}^{-2}\right)$, which increases toward the boundary and toward the inflow region. The heat loss over the inflowing Atlantic Water is over $1000 \mathrm{~W} \mathrm{~m}^{-2}$. The interior heat loss is similar to what is estimated for the Beaufort Sea (Maykut 1982; Krishfield and Perovich 2005). The increase toward the eastern boundary is also consistent with the estimates from Krishfield and Perovich (2005).

\section{The halocline and the cyclonic boundary current}

The main objective of this study is to gain insight into what maintains the halocline and basic circulation of Atlantic Water in the Arctic Ocean. Although the numerical model described in the previous section is quite idealized with respect to the real ocean, it does produce circulation patterns and transports, ice cover, and heat and freshwater fluxes that are in general accord with observational estimates and more realistic ocean models. As such, the numerical model is now used to aid in the development and testing of a conceptual model of the Arctic halocline and cyclonic Atlantic Water boundary current. The conceptual model will make clear how the basic characteristics of the Arctic depend on the buoyancy forcing and environmental parameters.

The mean circulation of Atlantic Water in the western basin, where the halocline is most developed, is along the sloping topography. A section of the temperature, salinity, and meridional velocity across the boundary current at $y=3100 \mathrm{~km}$ is shown in Fig. 8. The halocline is indicated by low temperature and salinity in the upper $200 \mathrm{~m}$ over the flat interior. Near the boundary, the halocline thins to the upper $50-100 \mathrm{~m}$ and gets fresher as the near-surface restoring region is approached. Below the halocline the water is relatively warm, salty, and weakly stratified. The warmest water (between $1.5^{\circ}$ and $2.0^{\circ} \mathrm{C}$ ) is found over the sloping bottom, but water between $1^{\circ}$ and $1.5^{\circ} \mathrm{C}$ is found throughout the interior. Recall that this layer was initialized at $-1.95^{\circ} \mathrm{C}$. A remnant of that cold initial water is still found below

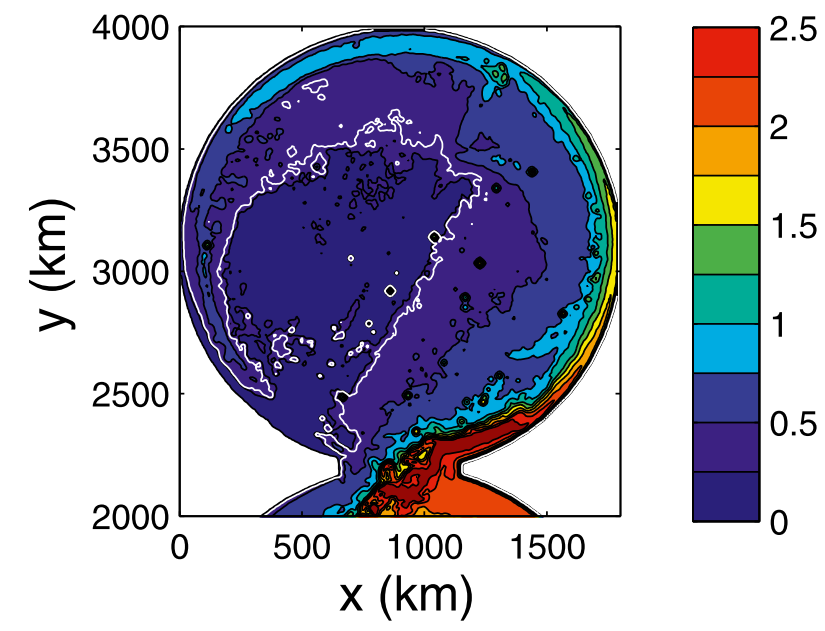

FIG. 7. Logarithm of the mean surface heat flux $\left(\mathrm{Wm}^{-2}\right)$. For reference, the $2 \mathrm{~W} \mathrm{~m}^{-2}$ contour is given in white.

800-m depth, where there remains a slow warming trend after 100 years integration. The velocity of the warm layer over the sloping bottom is $O\left(5 \mathrm{~cm} \mathrm{~s}^{-1}\right)$ and southward, marking the cyclonic boundary current. Similar velocities are observed in the Atlantic cyclonic boundary current (Woodgate et al. 2001, 2007; Aksenov et al. 2011). The Atlantic Water boundary current is largely barotropic below the halocline with most of the shear provided by the halocline slope.

The general pattern of high sea surface height and a deepening of the halocline in the basin interior is consistent with the observed hydrography of the Canada Basin as discussed, for example, by Zhang and Steele (2007). Their interpretation is that the anticyclonic wind stress curl in the Beaufort Gyre is responsible for the deepening of the halocline. A different mechanism is invoked here, namely the influence of vertical diffusion and the change of dynamical regimes from the boundary into the interior. While vertical diffusion is active throughout the basin, it results in a much deeper halocline in the interior than near the boundaries. This is because the lateral advection of high-salinity water required to balance the deepening due to vertical diffusion is very different over the sloping bottom than it is in the basin interior. The cyclonic boundary current advects high-salinity water in the Atlantic layer relatively quickly while the eddy flux into the basin interior is much slower. A rough scaling for the advective time scale in the boundary current is $l / V=3$ years, where $V=$ $0.05 \mathrm{~m} \mathrm{~s}^{-1}$ is the mean speed in the boundary current and $l=5 \times 10^{6} \mathrm{~m}$ is the perimeter of the basin. For a vertical diffusion of $10^{-5} \mathrm{~m}^{2} \mathrm{~s}^{-1}$, this time scale gives a diffusive deepening of the halocline within the boundary current of only $O(30 \mathrm{~m})$. However, the time scale of lateral eddy 

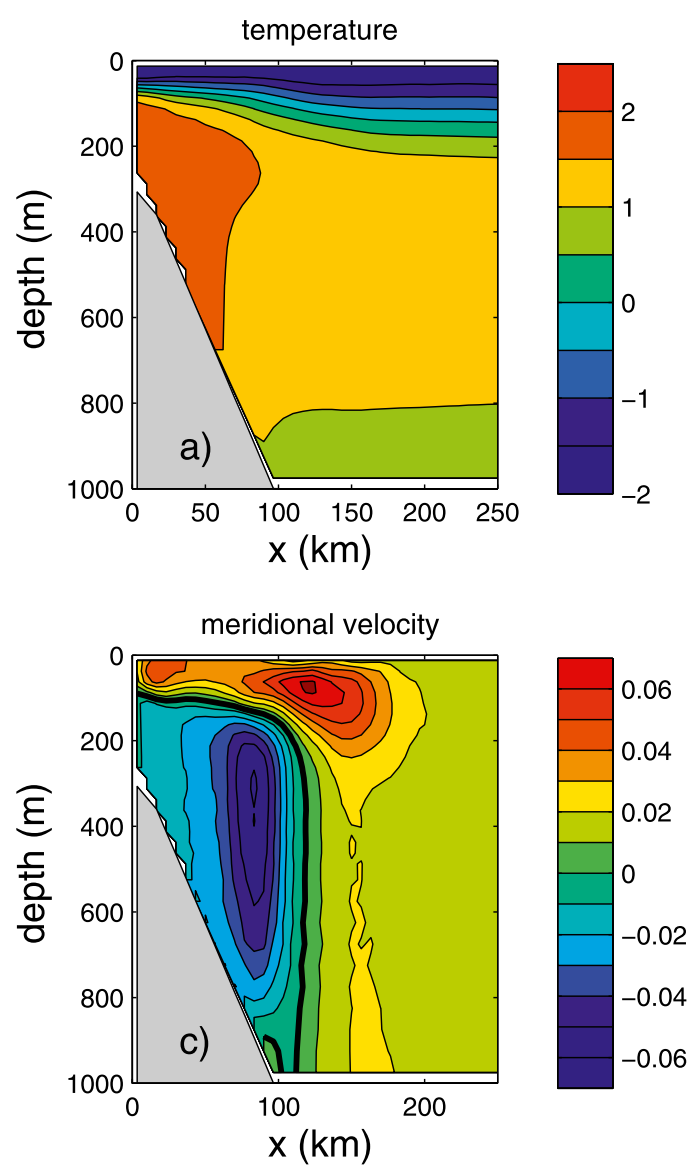

fluxes into the basin interior is much slower (as evident in the theory below), enabling vertical diffusion to deepen the halocline in the interior. This difference in dynamical regimes is what leads to the lateral gradient in the depth of the halocline seen in Fig. 8 and, through thermal wind, the cyclonic boundary current of Atlantic Water.

It is clear that heat and freshwater from the boundary region are transported into the basin interior in order to maintain the stratification and vertical heat flux found there. This transport is achieved by eddies formed from the boundary current over the sloping bottom. An example of eddies transporting freshwater off the western boundary at the surface is shown in Fig. 9a. (Eddies are defined as deviations from the time mean and as such may not always be characterized as isolated, coherent vortices.) There are two dominant horizontal scales that transport low-salinity surface waters offshore: larger meanders or protrusions of $O(100 \mathrm{~km})$ and very small features of $O(25 \mathrm{~km})$. It is likely that these smaller features are only marginally resolved with the $6.7-\mathrm{km}$ model grid, so higher resolution may enhance the role of these small eddies. The large features are found extending

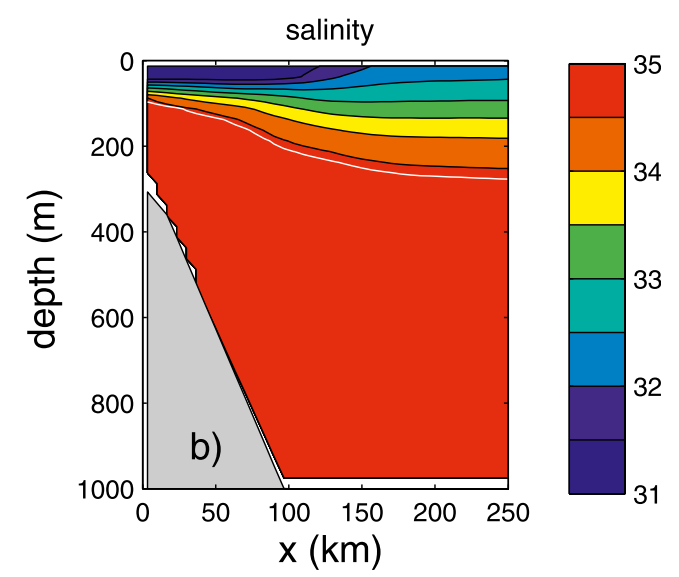

FIG. 8. Mean section along $y=3100 \mathrm{~km}$ near the western boundary. (a) Temperature $\left({ }^{\circ} \mathrm{C}\right)$, (b) salinity (halocline depth is given by the white line), and (c) meridional velocity $\left(\mathrm{m} \mathrm{s}^{-1}\right.$; thick line in the zero contour).

all the way down through the Atlantic Water, while the small-scale features are surface trapped and have signatures only in the upper part of the halocline (Fig. 9b). Sometimes the deep and shallow eddies appear to be coupled, but this is not always the case. This suggests that there are two unstable modes active in the exchange between the boundary and the interior, one acting on the lateral density gradient near the surface of the halocline, which has a small vertical scale $\left(h_{1}\right)$, and one acting on the density gradient of opposite sign at the base of the halocline, which has a much larger vertical scale $\left(h_{2}\right)$.

A variety of eddies carrying water from the boundary into the interior have been found in the interior of the Arctic basins in both the halocline and the deeper Atlantic layer (Aagaard and Carmack 1994; D'Asaro 1988; Manley and Hunkins 1985; Muench et al. 2000; Timmermans et al. 2008). The shallow halocline eddies in the Canada Basin most commonly contain cold and fresh waters of Pacific origin (Plueddemann et al. 1998), which are thought to be formed from the shelfbreak jet along the Chukchi and Beaufort Seas (Manley and Hunkins 1985; D'Asaro 1988; Pickart et al. 2005; Spall et al. 2008). Thermohaline 
a)
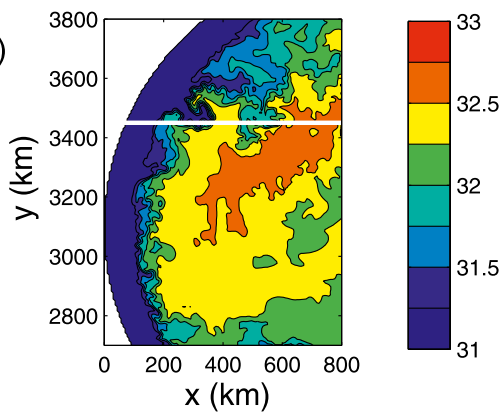

b)
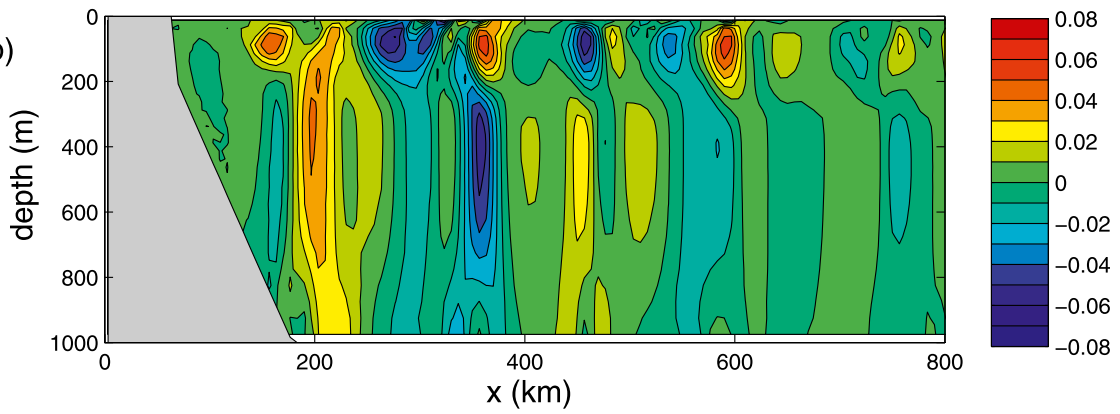

FIG. 9. (a) Salinity at $12.5-\mathrm{m}$ depth at the end of year 75 near the western boundary of the Arctic Basin. Low-salinity features are seen extending into the basin from the boundary on both small $(25 \mathrm{~km})$ and large $(100 \mathrm{~km})$ scales. (b) Vertical section of velocity $\left(\mathrm{m} \mathrm{s}^{-1}\right)$ normal to the white line in (a). Two types of eddies are seen: shallow eddies in the upper halocline and deep eddies in the Atlantic layer.

intrusions also appear to be an important mechanism for the lateral exchange of temperature and salinity anomalies between the boundary current and the interior (Walsh and Carmack 2003), although they occur on scales too small to be resolved in the present numerical model.

The lateral eddy salt flux and heat flux averaged around the perimeter of the western basin are shown as a function of distance from the boundary and depth in Fig. 10. The salt flux is negative in the upper $50 \mathrm{~m}$ and positive below. The change in sign of the salt flux occurs at the depth at which the horizontal gradient in the mean salinity changes sign. The negative eddy salt flux corresponds to the transport of freshwater toward the basin interior, while a positive flux is found for the transport of salty water. The pattern in Fig. 10a is indicative of an exchange
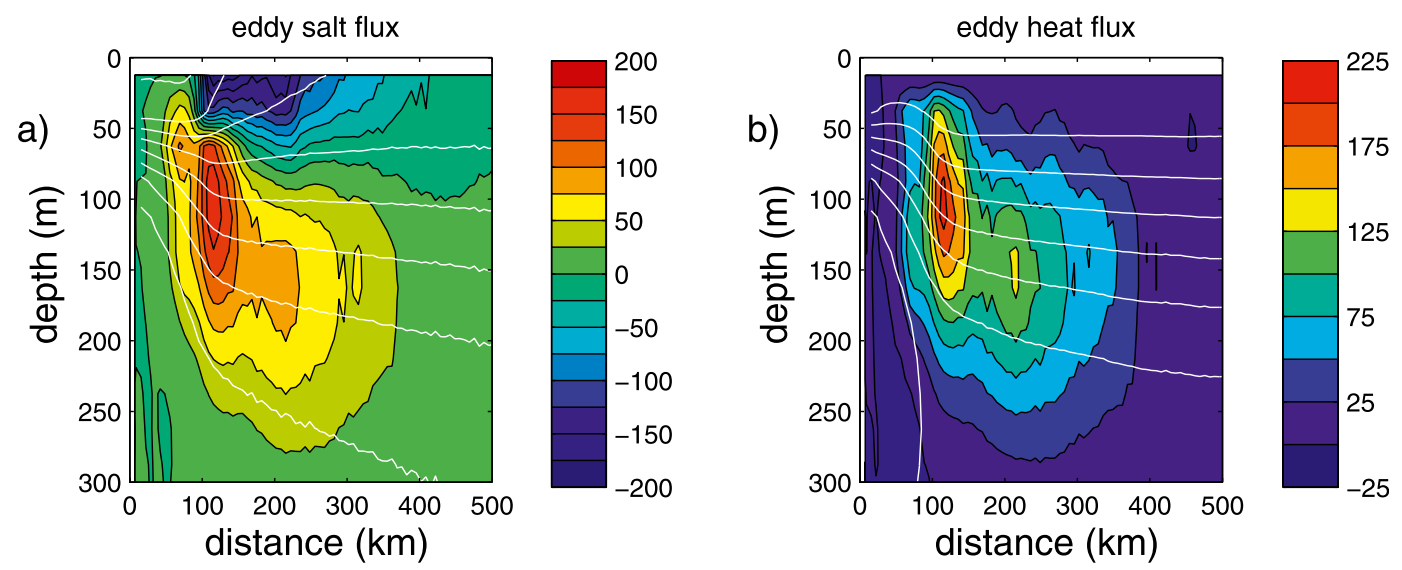

FIG. 10. Mean eddy fluxes averaged around the perimeter of the western basin as a function of depth and distance from the boundary. (a) Eddy salt flux $\left(\mathrm{m}^{2} \mathrm{~s}^{-1}\right)$ and (b) eddy temperature flux $\left(\mathrm{m}^{2}{ }^{\circ} \mathrm{Cs}^{-1}\right)$. White contours indicate mean salinity in (a) and temperature in (b). 
of water between the boundary current and the basin interior in both the upper and lower parts of the water column. This general pattern is to be expected because there is no freshwater flux at the surface in the interior and the mean flow across topographic contours is weak. This requires that the integrated lateral eddy salt flux from the boundary into the interior is small, so that there must be a balance between the upper- and lower-layer salt fluxes. This provides a key constraint for the analytic model below. The lateral eddy heat flux is positive throughout the water column (Fig. 10b). This is also consistent with eddies being shed from the boundary because the boundary current is warmer than the interior at all depths.

The eddy-driven exchange between the boundary and the interior motivates a simple three-layer approach to understanding the mean state of the boundary current and halocline. A similar two-layer model has been applied previously to convective basins subject to cooling (Spall 2004, 2010) and combined precipitation and cooling (Spall 2012). The main difference here is that the interior is not a homogeneous water mass, as assumed in these previous studies, but is instead characterized by a stratified halocline overlying a homogeneous layer of Atlantic Water (Fig. 11). The conceptual model consists of three layers: a cold, fresh surface layer around the basin perimeter; a warm, salty layer of Atlantic Water at depth; and a halocline of thickness $h_{c}$, extending from the surface to the Atlantic Water in the basin interior. The cold, fresh layer is of thickness $h_{1}$ and salinity $S_{1}$, both assumed to be known, and represents river runoff and inflow of Pacific Water. Processes on the shelf, not represented in either the numerical model or this simple analytic model, determine the thickness and salinity of this layer. The salinity and temperature of the Atlantic Water ( $S_{2}$ and $T_{2}$, respectively) are also assumed to be known because the Atlantic Water is largely isolated from the atmosphere once it enters the Arctic Ocean. These two water masses constitute the forcing in this conceptual model. The halocline is assumed to be uniformly stratified with surface salinity $S_{0}$ and salinity of $S_{2}$ at a depth of $h_{c}$.

A salt balance may be written for the interior of the basin as

$$
P h_{1} \overline{v_{1}^{\prime} S_{1}^{\prime}}+P h_{2} \overline{v_{2}^{\prime} S_{2}^{\prime}}=-A E S_{0},
$$

where $P$ is the basin perimeter, $A$ is the surface area in the basin interior, the eddy salt fluxes are the component into the basin interior, and $E$ is the net evaporation minus precipitation (included here for completeness, but taken to be zero for the remainder of the study). A possible solution, in the absence of precipitation or evaporation, is that the eddy fluxes from the boundary

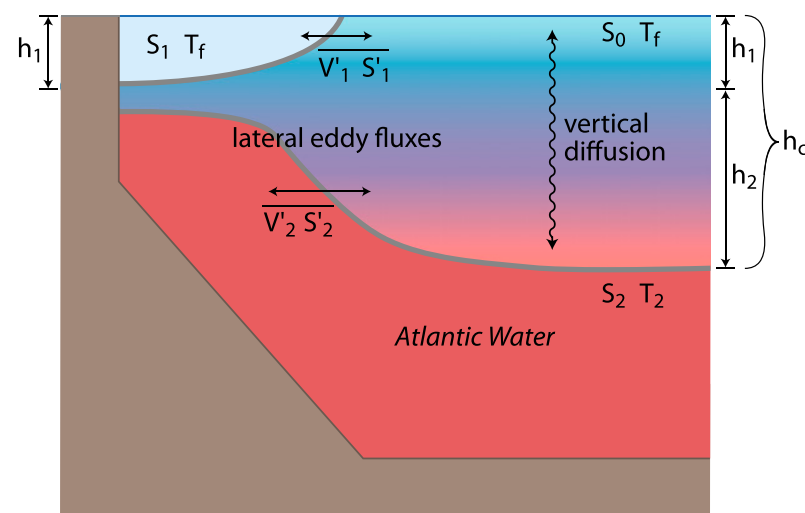

FIG. 11. Schematic of the three-layer model consisting of the cold, fresh shelf water of thickness $h_{1}$ and salinity $S_{1}$; the warm, salty Atlantic Water of salinity $S_{2}$ and temperature $T_{2}$; and the stratified halocline of thickness $h_{c}=h_{1}+h_{2}$ with surface salinity $S_{0}$ and temperature at the freezing point $T_{f}$. Lateral eddy fluxes from the boundary currents across sloping isohalines balance vertical diffusion in the halocline interior.

are zero in both layers 1 and 2. This would result in uniform salinity and thickness for the upper layer and an infinitely sharp transition from $S_{1}$ to $S_{2}$ at depth $h_{1}$. However, any mixing in the interior would then make steady-state solutions impossible because there would be no way to balance the diffusive flux. The alternative is that the net freshwater flux offshore in each layer is balanced by vertical diffusion within the halocline. In other words, the freshwater fluxed offshore in the upper layer is diffused downward to balance the salt fluxed offshore in the lower layer. This then requires that

$$
P h_{2} \overline{v_{2}^{\prime} S_{2}^{\prime}}=\frac{\kappa\left(S_{2}-S_{0}\right) A}{h_{1}+h_{2}},
$$

where $\kappa$ is a constant vertical diffusion coefficient.

The eddy fluxes will be parameterized following Visbeck et al. (1996) and Spall (2004) to be proportional to the product of baroclinic shear in the boundary current and the change in salinity between the boundary current and the interior:

$$
\begin{gathered}
\overline{v_{k}^{\prime} S_{k}^{\prime}}=c_{k} V_{k}\left(S_{k}-S_{i k}\right) \quad \text { and } \\
V_{k}=\frac{g \beta_{S}\left(S_{k}-S_{i k}\right) h_{k}}{\rho_{0} f_{0} L} .
\end{gathered}
$$

The subscript $k$ refers to the layer and $V_{k}$ is the baroclinic shear across layer $k$. The salinity $S_{i k}$ is the halocline salinity averaged over $h_{k}$. A simple linear equation of state is assumed as $\rho=\rho_{0}+\beta_{S}(S-35)$. The nondimensional $c_{k}$ has been found to be nearly constant at 0.025 for a variety of flat bottom models and laboratory 
experiments of baroclinic instability (Visbeck et al. 1996). The constant decreases for a sloping bottom roughly in accordance with linear instability theory and, for steep topography, $c$ is typically reduced by an order of magnitude (Spall 2004; Isachsen 2011). It is assumed that the stratification is sufficiently strong that the upper layer does not feel the bottom slope, so that $c_{1}=0.025 ; c_{2}$ will be taken to be 0.0025 for calculations with topography and 0.025 for the calculation with a flat bottom. Although this choice is not well constrained, the results below are not overly sensitive to the value of $c_{2}$. The main point is that $c_{2} \ll c_{1}$ for cases with bottom topography.

It is assumed that the upper and lower layers can be parameterized separately, as in (4). There are at least two other possibilities. One is that the upper layer is passive with temperature and salinity anomalies carried off the boundary in the upper layer by instabilities that grow on baroclinic shear $V_{2}$. The parameter dependencies that result from this assumption are nearly the same as is found below, differing only by an $O(1)$ constant. A second possibility is that the two layers are coupled and the fluxes depend in some more complicated way on the layer thicknesses and mean shear. While this seems possible, simple parameterizations as (4) are not available for such a system and so it will not be considered further.

If it is assumed that the halocline layer is uniformly stratified, the vertically averaged change in salinity between the boundary and the interior may be written as

$S_{1}-S_{i 1}=S_{1}-S_{0}-0.5\left(S_{2}-S_{0}\right) h_{1} /\left(h_{1}+h_{2}\right)$ and

$S_{2}-S_{i 2}=0.5\left(S_{2}-S_{0}\right) h_{2} /\left(h_{1}+h_{2}\right)$.

In the interest of obtaining simple analytic solutions, it is assumed that $h_{1} \ll h_{2}$, or that the halocline is deep compared to the thickness of the freshwater coming off the shelf. This is generally a good assumption, and eliminates the second term on the right-hand side in (6) and the scale factor proportional to $h_{2} /\left(h_{1}+h_{2}\right)$ in (7). It is equivalent to assuming that salinity is constant from the surface down to depth $h_{1}$.

Making use of (4), (5), (6), and (7), there are now two equations [(2) and (3)] and two unknowns: the surface salinity in the interior $S_{0}$ and the layer thickness $h_{2}$. These can be combined to obtain a single equation for $S_{0}$. It is useful at this point to nondimensionalize the equations, representing the surface salinity $S_{0}$ through a scaled salinity anomaly $\Delta$ as

$$
\Delta=\frac{S_{0}-S_{1}}{S_{2}-S_{1}} .
$$

For surface salinity approaching that coming off the shelf, $\Delta \rightarrow 0$. For a surface salinity equal to that of the Atlantic Water, $\Delta \rightarrow 1$. This results in a cubic equation for the surface salinity $\Delta$

$$
\Delta^{3}-\lambda(1-\Delta)^{2}=0
$$

where

$$
\lambda=\frac{\rho_{0} f_{0} L \kappa A c_{2}^{0.5}}{2 g \beta_{S} P c_{1}^{1.5} h_{1}^{3}\left(S_{2}-S_{1}\right)} .
$$

It can be shown that there is only one physically consistent solution with $0<\Delta<1$. The nondimensional constant $\lambda$ controls the solution and is entirely determined by the parameters that define the problem. It can be interpreted as the eddy advective time scale over the diffusive time scale.

The halocline thickness, nondimensionalized by the freshwater layer thickness near the boundary (i.e., $h_{1}$ ), can then be written as

$$
h_{c}=1+2\left(c_{1} / c_{2}\right)^{0.5} \frac{\Delta}{1-\Delta} .
$$

The halocline approaches the thickness of the near boundary shelf water as $\Delta \rightarrow 0$, while the halocline becomes infinitely deep as $\Delta \rightarrow 1$. The halocline depth also depends on the relative efficiency of the eddy fluxes. For a sloping bottom, $c_{2} \ll c_{1}$ and $h_{c}>1$. For a flat bottom, $c_{2}=c_{1}$ and, for the same surface salinity, the halocline will be thinner.

Another quantity of interest is the freshwater content of the halocline. This is the vertically integrated salinity relative to a reference salinity $S_{r}$, as in (1). The nondimensional reference salinity may be defined by $\delta=$ $\left(S_{2}-S_{r}\right) /\left(S_{2}-S_{1}\right)$. It is assumed that the reference salinity is $90 \%$ between the lowest salinity $S_{1}$ and the Atlantic Water salinity $S_{2}$, or $\delta=0.1$. The freshwater content may then be written as the sum of the freshwater anomalies integrated over each layer thickness. This can be written in dimensional form as

$$
F=0.5\left(S_{r}-S_{0}\right) \frac{h_{2}\left(S_{r}-S_{0}\right)}{S_{2}-S_{0}}+\left(S_{r}-S_{0}\right) h_{1} .
$$

The first term is the contribution from the salinity anomaly over layer $h_{2}$, which is the product of the average salinity anomaly relative to $S_{r}$ and the layer thickness for which the salinity exceeds $S_{r}$. The second term is the contribution from the upper layer, assumed here to be of uniform salinity $S_{0}$. This may be written in nondimensional terms as 


$$
F=\left(\frac{c_{1}}{c_{2}}\right)^{0.5} \frac{\Delta(1-\Delta-\delta)^{2}}{(1-\Delta)^{2}}+1-\Delta-\delta .
$$

The solutions are controlled by the nondimensional parameter $\lambda$. For $\lambda \ll 1$, the lateral eddy fluxes are large. This requires a sharper halocline (thin, fresh) for vertical diffusion to be able to balance the eddy fluxes. For $\lambda \gg 1$, the halocline is deep and relatively salty. In this limit, the eddy fluxes are weak, allowing diffusion to deepen the halocline and diffuse salt upward. Wide variation in $\lambda$ is most easily controlled by variations in the vertical diffusion $\kappa$ because the other parameters are more strongly constrained by basin geometry and the range of typical oceanic parameters. The system is also sensitive to the shelf depth or the thickness of the freshwater near the boundary. Increasing the vertical diffusion or surface area makes the system more diffusive (increases $\lambda$ ), while increasing the lateral flux by eddies from the boundary (increasing the perimeter $P$, the source of freshwater through $h_{1}$ or $S_{2}-S_{1}$, or the velocity of the boundary current through decreasing $f_{0}$ or $L$ or increasing $\beta_{S}$ ) makes the halocline thinner and fresher (decreases $\lambda$ ).

Solutions for the halocline thickness, surface salinity, and freshwater content are shown in Fig. 12 as a function of $\lambda$. The halocline depth varies most strongly with $\lambda$, increasing as $\lambda^{0.5}$ for $\lambda \gg 1$. The halocline depth varies from the freshwater layer thickness for small $\lambda$ to about 70 times this thickness for $\lambda=10^{2}$. The surface salinity varies smoothly from $S_{1}$ for $\lambda \ll 1$ to $S_{2}$ for $\lambda \gg 1$. It is not clear from (13) how the freshwater content depends on $\lambda$ because we can expect it to increase with increasing layer thickness and to decrease with increasing salinity, both of which happen as $\lambda$ increases. For very weak mixing, or small $\lambda$, the freshwater content approaches 1 . This means that the surface water near the boundary has simply spread over the interior and has maintained its low salinity and layer thickness. As $\lambda$ increases, the freshwater content increases until $\lambda=O(1)$, where it peaks at about $50 \%$ more freshwater content than is near the boundary. For weak mixing, the theory predicts a lateral gradient in freshwater content and halocline depth, as is observed, as a result of eddy fluxes and vertical mixing, even in the absence of wind stress curl in the basin interior. Further increases in $\lambda$ result in a decrease in $F$ because of the increase in the salinity of the halocline. As the salinity approaches the reference salinity, the freshwater content goes to zero.

The value of $\lambda$ for the real Arctic Ocean is difficult to calculate with much certainty, but a rough estimate is possible. Typical parameters for the Canada Basin are $f_{0}=1.4 \times 10^{-4} \mathrm{~s}^{-1}, L=10^{5} \mathrm{~m}, \kappa=10^{-6}-10^{-5} \mathrm{~m}^{2} \mathrm{~s}^{-1}$, $A=7 \times 10^{12} \mathrm{~m}^{2}, P=10^{7} \mathrm{~m}, \beta_{S}=0.8 \mathrm{Kg} \mathrm{m}^{-3}, c_{1}=0.025$, $c_{2}=0.0025, h_{1}=50 \mathrm{~m}$, and $S_{2}-S_{1}=5$. This gives

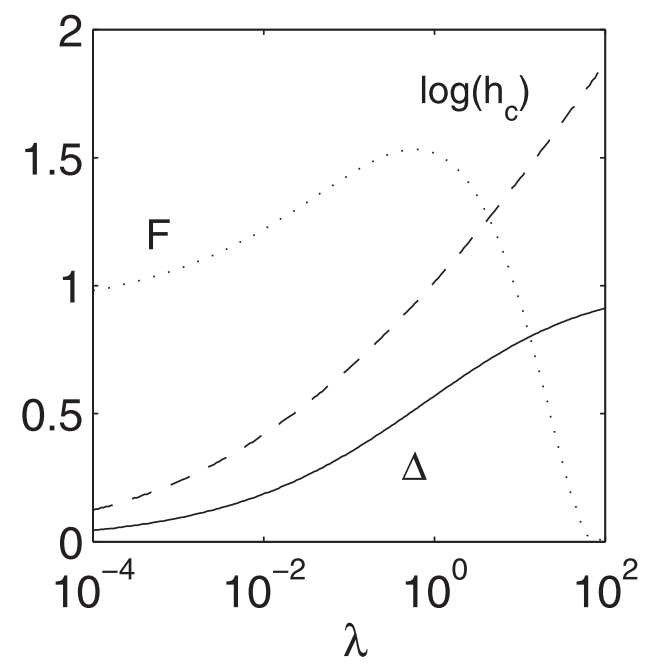

FIG. 12. Solutions for the nondimensional surface salinity $\Delta$ (solid line), log of the halocline depth $h_{c}$ (dashed line), and the freshwater content $F$ (dotted line) from (9), (11), and (13).

a value of $\lambda \approx 10^{-2}-10^{-1}$. Taking parameters as used for the numerical model results described in section 2 , $\lambda=0.08$.

The nondimensional formulation makes for a compact and intuitive presentation, but the controlling parameter $\lambda$ is not a familiar one and interpreting the results in terms of the real Arctic Ocean is difficult. The theory is now compared directly with results from the numerical model for a range of values of the vertical diffusivity. The theory predicts a halocline depth of $224 \mathrm{~m}$, while the average halocline depth within the circle indicated on Fig. 6a is $270 \mathrm{~m}$. The surface salinity predicted by the theory is 32.31 , while that found in the model is 32.38 . These results are indicated graphically on Fig. 13 by the asterisk. Model runs with higher and lower values of $\kappa$ have also been carried out, as indicated by the squares. ${ }^{1}$ The general pattern and magnitude of the halocline depth and surface salinity predicted by the theory compare well with the model results. The model slightly over predicts the halocline depth for all values of $\kappa$; however, the dependence on diffusivity is fairly well represented. For $\kappa<10^{-6} \mathrm{~m}^{2} \mathrm{~s}^{-1}$, it is likely that numerical diffusion due to the advection scheme is becoming important, and so the results may have reached a practical limit controlled by model resolution and numerics. However, the theory suggests that reasonable halocline thicknesses and surface salinities are maintained with relatively small values of vertical mixing

\footnotetext{
${ }^{1}$ Each of these runs are only 50-years long, but the halocline properties show little drift after 40-years integration.
} 

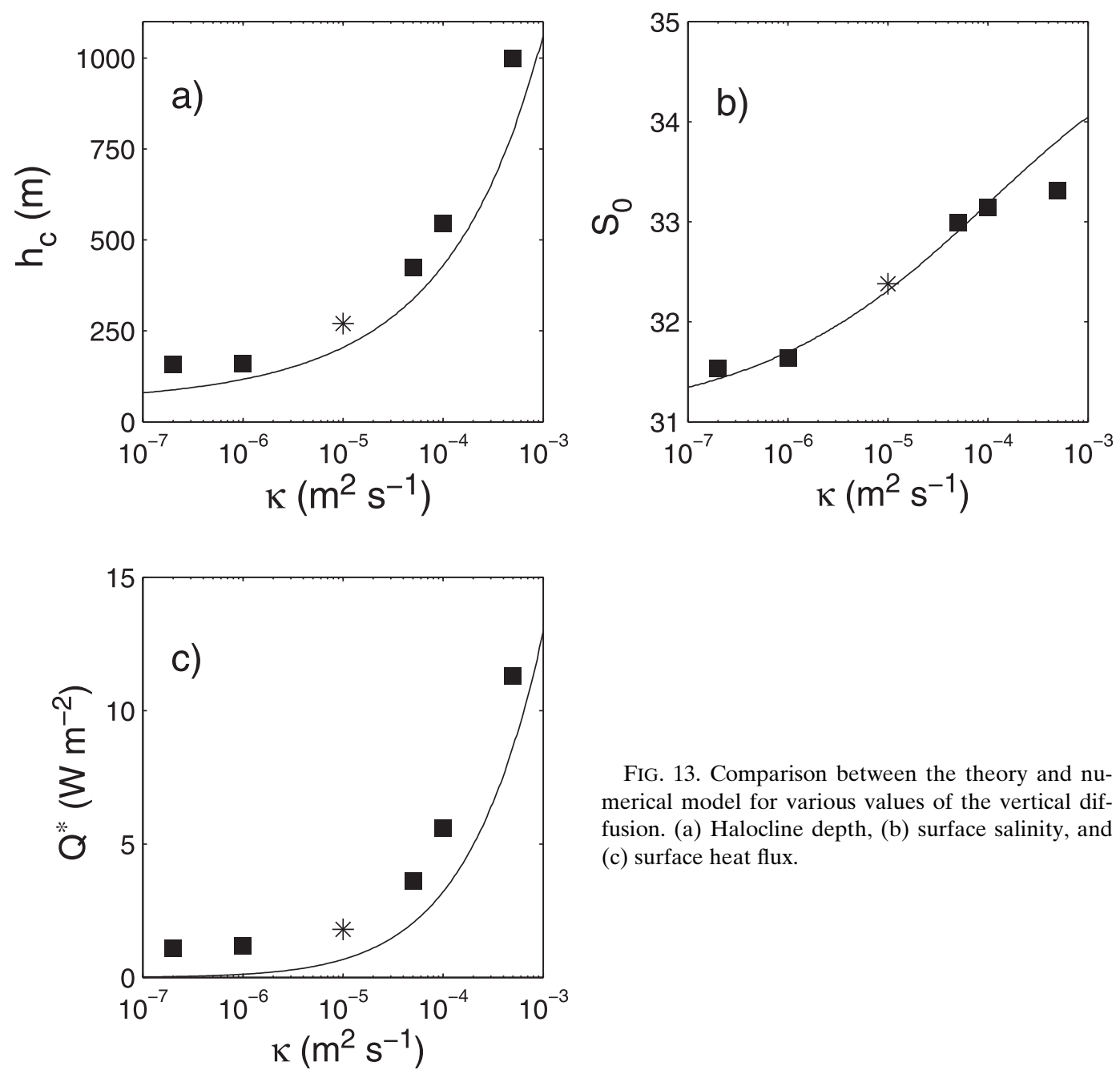

FIG. 13. Comparison between the theory and numerical model for various values of the vertical diffusion. (a) Halocline depth, (b) surface salinity, and (c) surface heat flux.

$\left(10^{-6}-10^{-5} \mathrm{~m}^{2} \mathrm{~s}^{-1}\right)$. Observational estimates of vertical mixing in the halocline are limited; however, Fer (2009) and Rainville and Winsor (2008) report vertical diffusion coefficients within the cold halocline of $10^{-6}-$ $10^{-5} \mathrm{~m}^{2} \mathrm{~s}^{-1}$. The model salinity for $\kappa=5 \times 10^{-4} \mathrm{~m}^{2} \mathrm{~s}^{-1}$ is lower than predicted by the theory (Fig. 13b). This is because the deep salinity is reduced by the very large vertical diffusion to 34.1, while the curve assumes $S_{2}=35$ for all values of $\kappa$. The model surface salinity compares well with the theory if $S_{2}$ is taken to be 34.1 instead of 35 (this is done in Fig. 14b).

Another quantity of interest for maintenance of the ice cover and for climate is the heat loss from the ocean to the ice. This can be calculated from the theory, once the halocline depth is known, as the vertical diffusion of heat from the Atlantic Water through the halocline:

$$
Q=\rho_{0} C_{p} \kappa\left(T_{2}-T_{f}\right) / h_{c}
$$

where the surface temperature has been assumed to be the freezing temperature of water $T_{f}$. The heat flux predicted by (14) is compared to the average surface heat flux in the basin interior in Fig. 13c. The theory predicts the dependence on $\kappa$ fairly well, although it consistently under predicts the heat flux by $O\left(1 \mathrm{~W} \mathrm{~m}^{-2}\right)$. This is likely due to advective effects in the model. The theory assumes that all heat is diffused upward from the Atlantic Water layer; however, the eddies shed from the boundary carry heat into the interior throughout the halocline (Fig. 10b). This provides an advective means to get heat near the surface in addition to diffusion from below. There may also be some upward diffusion owing to model numerics for small $\kappa$, as surmised from the halocline depth.

The theory also predicts that the halocline properties depend on other parameters, such as the salinity and thickness of the surface layer near the boundary, the Coriolis parameter, and the bottom slope (through the constant $c_{2}$ ). The model has been run for 50 years varying 

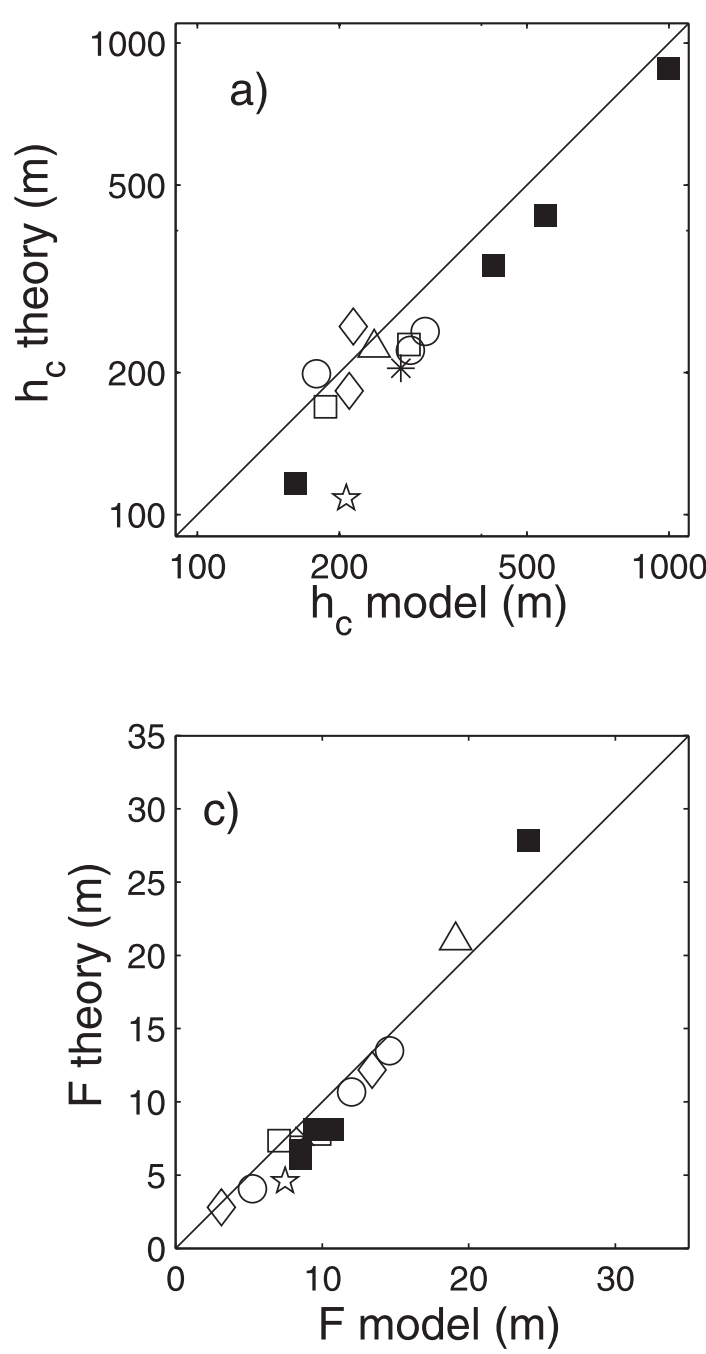

each of these parameters and the halocline properties have been diagnosed. The model runs are summarized in Table 1 . The surface salinity near the boundary has been restored toward values ranging from 29 to 33, the thickness of freshwater near the boundary $h_{1}$ has been restored to 25,75 , and $100 \mathrm{~m}$, the Coriolis parameter was varied by $\pm 50 \%$ and, finally, the bottom slope around the Arctic Basin was flattened. In the theory for this calculation, the stability constant for the second layer was set to the same value as for the first layer $\left(c_{2}=0.025\right)$-appropriate for baroclinic instability over a flat bottom. The diagnosed halocline depth for each of these calculations compares reasonably well with the theory (Fig. 14a). Although the halocline thickness is most sensitive to the vertical diffusivity, the general trend predicted for these other parameters is reproduced in the numerical model. A notable dependence is that the halocline depth is much thinner for the flat bottom calculation (star; $195 \mathrm{~m}$ versus $270 \mathrm{~m}$ for sloping bottom). This is

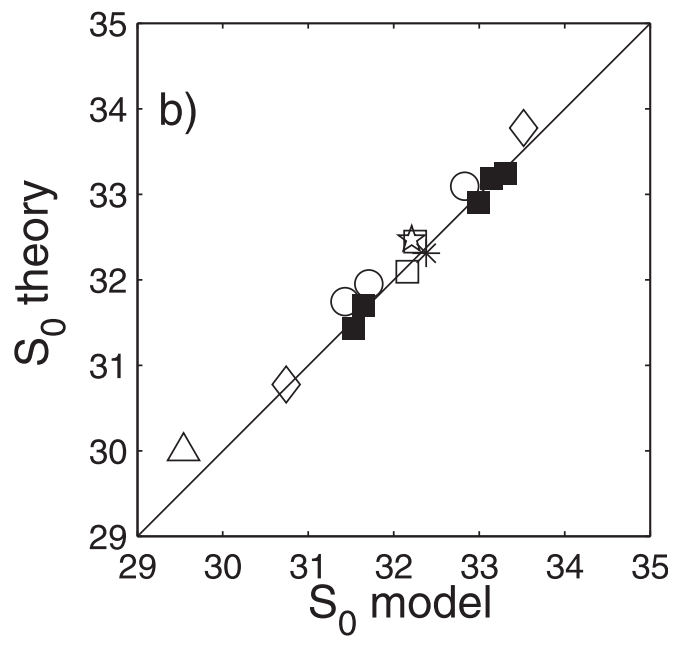

FIG. 14. Comparison between model and theory for each of the numerical calculations in Table 1 . (a) Halocline depth, (b) surface salinity, and (c) freshwater content. because, with a flat bottom, the Atlantic Water boundary current is much more unstable, resulting in a stronger flux of salt offshore for a given baroclinic shear. Because this offshore flux must be diffused upward, the halocline thins such that 1) the baroclinic shear is less (reducing the eddy flux) and 2) the vertical salt diffusion is increased.

The surface salinity in the model for each of these runs is compared to the theory in Fig. 14b. Not surprisingly, the surface salinity depends strongly on the surface salinity near the boundary (diamonds), but depends only weakly on the Coriolis parameter (squares) and the bottom slope (star). Thicker freshwater layers near the boundary also result in a fresher halocline. The freshwater content is also well predicted by the theory (Fig. 14c). As expected, the freshwater content increases considerably for increasing freshwater near the boundary (salinity $S_{1}$ or thickness $h_{1}$ ). The flat bottom also reduces the freshwater content. 
TABLE 1. Summary of model runs with key parameters: shelf water depth $h_{1}(\mathrm{~m})$, shelf salinity $S_{1}$, vertical diffusion $\kappa\left(\mathrm{m}^{2} \mathrm{~s}^{-1}\right)$, Coriolis parameter $f_{0}\left(10^{-4} \mathrm{~s}^{-1}\right)$, and $c_{2}$. The model-diagnosed quantities: halocline depth $h_{c}(\mathrm{~m})$, surface salinity $S_{0}$, freshwater content $F(\mathrm{~m})$, surface heat flux $Q\left(\mathrm{~W} \mathrm{~m}^{-2}\right)$, and transport of Atlantic Water $\Psi(\mathrm{Sv})$. The second column indicates the symbols used in the figures to illustrate (in most cases) variations of a single parameter.

\begin{tabular}{|c|c|c|c|c|c|c|c|c|c|c|c|}
\hline Run & Symbol & $h_{1}$ & $S_{1}$ & $\kappa$ & $f_{0}$ & $c_{2}$ & $h_{c}$ & $S_{0}$ & $F$ & $Q$ & $\Psi$ \\
\hline 1 & Asterisk & 50 & 31 & $10^{-5}$ & 1.2 & 0.0025 & 270 & 32.38 & 8.82 & 1.80 & 2.15 \\
\hline 2 & Square & 50 & 31 & $10^{-5}$ & 1.2 & 0.0025 & 161 & 31.64 & 8.54 & 1.43 & 2.23 \\
\hline 3 & Square & 50 & 31 & $5 \times 10^{-5}$ & 1.2 & 0.0025 & 424 & 32.99 & 9.45 & 2.75 & 2.75 \\
\hline 4 & Square & 50 & 31 & $10^{-4}$ & 1.2 & 0.0025 & 546 & 33.14 & 10.7 & 3.43 & 0.51 \\
\hline 5 & Square & 50 & 31 & $5 \times 10^{-4}$ & 1.2 & 0.0025 & 1000 & 33.31 & 24.1 & 5.59 & 0.0 \\
\hline 6 & Square & 50 & 31 & $2 \times 10^{-7}$ & 1.2 & 0.0025 & 159 & 31.53 & 8.50 & 1.32 & 2.15 \\
\hline 7 & Star & 50 & 31 & $10^{-5}$ & 1.2 & 0.025 & 195 & 32.18 & 7.34 & 2.54 & 1.08 \\
\hline 8 & Circle & 75 & 31 & $10^{-5}$ & 1.2 & 0.0025 & 283 & 31.71 & 12.0 & 1.87 & 2.39 \\
\hline 9 & Circle & 25 & 31 & $10^{-5}$ & 1.2 & 0.0025 & 179 & 32.83 & 5.23 & 2.41 & 2.04 \\
\hline 10 & Circle & 100 & 31 & $10^{-5}$ & 1.2 & 0.0025 & 304 & 31.43 & 14.6 & 1.71 & 2.43 \\
\hline 11 & Diamond & 50 & 33 & $10^{-5}$ & 1.2 & 0.0025 & 214 & 33.52 & 4.24 & 2.33 & 2.33 \\
\hline 12 & Diamond & 50 & 29 & $10^{-5}$ & 1.2 & 0.0025 & 211 & 30.74 & 12.0 & 2.32 & 2.76 \\
\hline 13 & Square & 50 & 31 & $10^{-5}$ & 0.6 & 0.0025 & 187 & 32.16 & 7.05 & 2.51 & 2.04 \\
\hline 14 & Square & 50 & 31 & $10^{-5}$ & 1.8 & 0.0025 & 281 & 32.25 & 9.83 & 1.34 & 2.38 \\
\hline 15 & Triangle & 100 & 29 & $10^{-5}$ & 1.2 & 0.0025 & 237 & 29.54 & 19.1 & 2.83 & 3.30 \\
\hline
\end{tabular}

\section{Transport of Atlantic Water}

The predictions from the three-layer model of the halocline/boundary current system compare reasonably well with diagnostics from the numerical model. These measures, however, deal primarily with the baroclinic structure of the boundary current, while a quantity of much interest is the transport of Atlantic Water in the cyclonic boundary current. This requires, in addition to the baroclinic shear, knowledge of a reference velocity, or the barotropic mode, for the boundary current. Because the buoyancy budgets, baroclinic instability parameterization, and thermal wind constraints used in the above theory depend only on the baroclinic shear, they cannot be used to estimate the barotropic mode. It also cannot be assumed that the deep velocity is weak so that a dynamic height could be calculated relative to a level of no motion, as in Steele and Ermold (2007). If the velocity at any depth could be predicted then, using the above theory, one could directly estimate the boundary current transport and its dependence on the parameters of the system.

While a general theory for the barotropic mode is not available, the model output has been used to identify a useful relationship between the sea surface height change across the boundary current and the change in freshwater content across the boundary current. A similar relationship between sea surface height and freshwater content has been previously seen in the Arctic in both general circulation models (Zhang and Steele 2007) and observations (Steele and Ermold 2007; Morison et al. 2012). A least squares fit of the change in sea surface height versus the change in freshwater content across the boundary current was obtained for each model calculation. Figure 15 shows that these quantities are approximately linearly related with a slope of $\alpha=0.0078$. The theory provides an estimate of the change in freshwater content between the boundary and the interior $\left(F-F_{b}\right)$, where $F_{b}=\left(S_{r}-S_{1}\right) h_{1} / S_{r}$ is the freshwater content near the boundary. This may be used with the empirical result to get an estimate of the change in sea surface height. Assuming a geostrophic momentum balance at the surface, this provides a reference velocity from which estimates of the absolute transport in the boundary current can be obtained. The total transport of

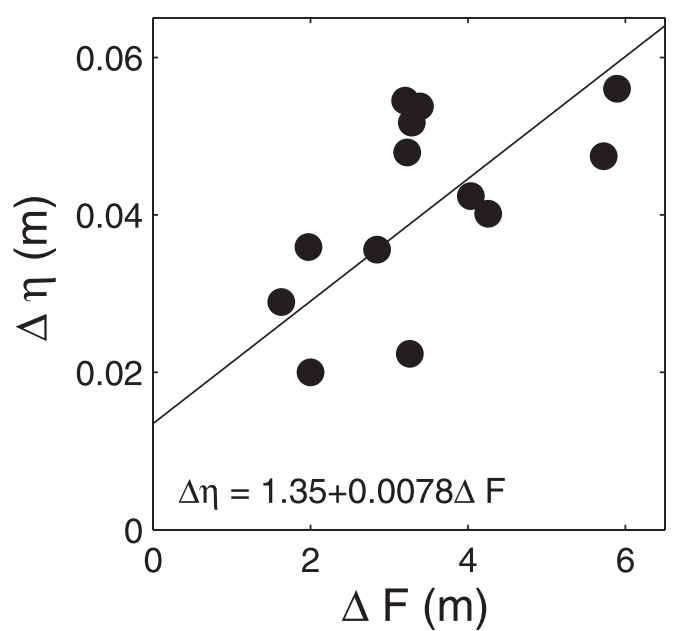

FIG. 15. Empirical relationship between the change in freshwater content across the boundary current in the western Arctic Basin and the change in sea surface height $\Delta \eta$ for each of the model runs in Table 1. 

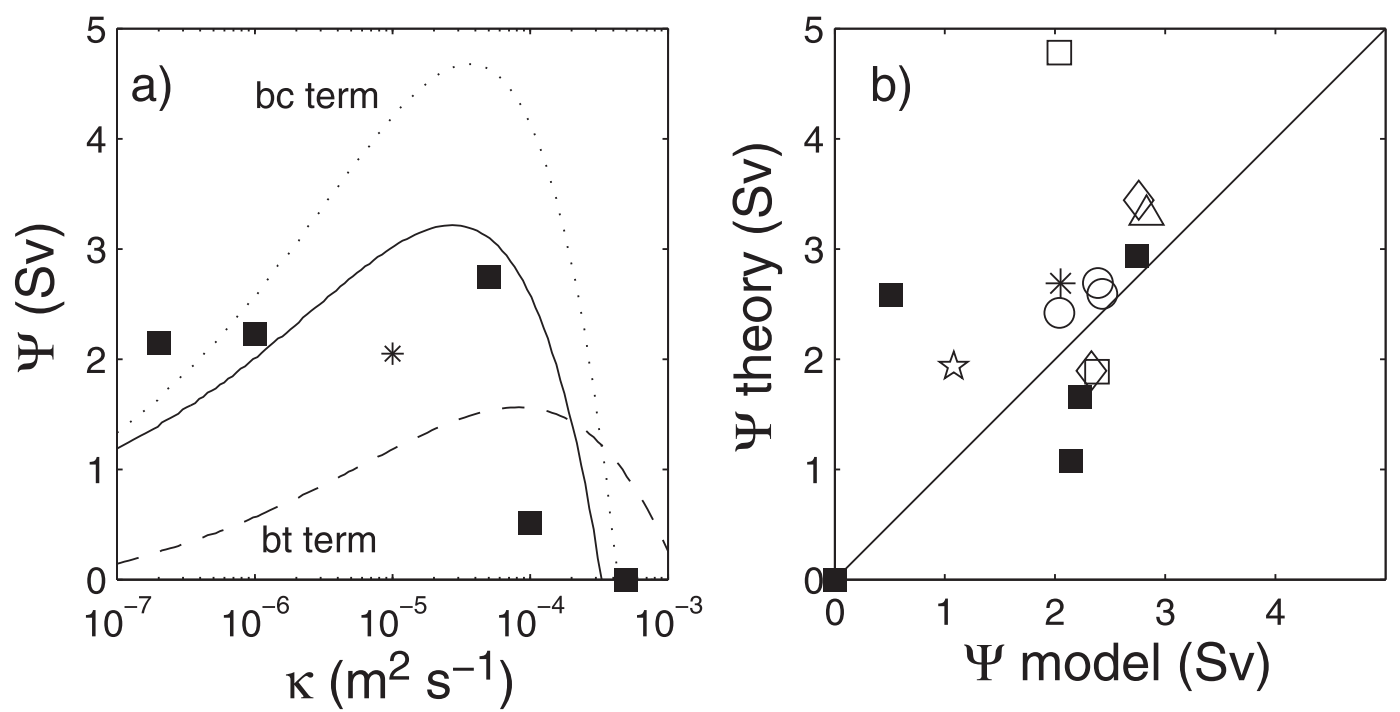

FIG. 16. Mean transport in the cyclonic Atlantic Water boundary current at $y=3100 \mathrm{~km}$. (a) As a function of vertical diffusion from the model runs (symbols) and full theory (solid line); sea surface height term (dashed line); and baroclinic shear term (dotted line) in (15). (b) Transport in the model compared to the theory for each of the model runs in Table 1.

Atlantic Water in the cyclonic boundary current can then be written as

$$
\Psi=\frac{g \alpha\left(F-F_{b}\right) H}{f_{0}}-\frac{g \beta_{S}\left(S_{2}-S_{i 2}\right) h_{2}\left(H-h_{1}-h_{2}\right)}{2 \rho_{0} f_{0}} .
$$

The first term is the northward transport due to the sloping sea surface height, integrated over the full depth of the water column $H$ (the barotropic term). The second term is the baroclinic shear due to the downward sloping isohalines as the halocline deepens into the interior, integrated over a depth $h_{2}$ (the baroclinic term). This gives rise to a barotropic transport over the depth below the halocline $\left(H-h_{1}-h_{2}\right)$. This baroclinic shear is generally large enough to overcome the sea surface height gradient and result in a southward (cyclonic) transport of Atlantic Water (e.g., Fig. 8). The magnitude of the southward transport predicted from (15) is shown in Fig. 16a as a function of $\kappa$, all other parameters as for the central calculation. One would see the same functional dependence on $\lambda$. The baroclinic term generally dominates the barotropic term, making the overall behavior less dependent on the empirical relationship used to obtain the barotropic mode. The theory predicts transports of $O(1-2 \mathrm{~Sv})$ for weak mixing. It is interesting that the magnitude of the Atlantic Water circulation is relatively insensitive to variations in $\kappa$ (or $\lambda$ ) in the weak mixing regime. Because there are two competing effects, the transport changes by only a factor of $O(2)$ for a change in mixing by three orders of magnitude. As mixing gets weak, the halocline becomes shallower $\left(h_{2} \rightarrow 0\right)$, which reduces the baroclinic shear. However, as mixing becomes weak the salinity within the halocline decreases, increasing the density anomaly and the lateral density gradient $\beta_{S}\left(S_{2}-S_{i 2}\right)$, which increases the baroclinic shear.

For sufficiently large mixing ( or $\lambda$ ), the direction of flow in the lower layer is reversed. In this case, there is a strong basin-scale anticyclonic circulation at all depths, eliminating the cyclonic boundary current of Atlantic Water. There are three competing effects. The transport initially increases with increasing diffusivity because the halocline deepens and the baroclinic shear is integrated over $h_{2}$. However, as the halocline gets very deep, the thickness of the Atlantic Water layer below the halocline is reduced (the $H-h_{1}-h_{2}$ term). There is also a smaller effect of reduced transport for increasing diffusivity because the lateral density gradient, $\beta_{S}\left(S_{2}-S_{i 2}\right)$, is reduced. The model transport is roughly in accord with the theory with values of $O(2 \mathrm{~Sv})$ for weak diffusivity and rapidly decreasing to zero with large diffusivity. The model fails to reproduce the reduction in transport for very weak diffusion, most likely because of numerical diffusion limiting the properties of the halocline (Fig. 13a).

A similar dependence of the strength and direction of the circulation of Atlantic Water in the Canada Basin on vertical diffusion was found in a series of comprehensive general circulation models by Zhang and Steele (2007). 
Their interpretation relied more heavily on the influences of anticyclonic wind stress curl in the Beaufort Gyre, but also noted that the depth and salinity of the halocline varied in the same sense as predicted here and that this played a central role in the strength of the cyclonic Atlantic Water boundary current.

The transport predicted by the theory is compared to the model transport for all of the runs in Fig. 16b. Most calculations compare well, and show little sensitivity of the transport to the model parameters. This is because most model runs are carried out with $\lambda=O\left(10^{-1}\right)$, which is near the theoretical peak in Atlantic Water transport. The largest discrepancies are generally found for the variations in $\kappa$ but, as seen in Fig. 16a, this is due to small errors in $h_{c}$ for small $\kappa$ and a rapid transition to weak Atlantic Water transport for large $\kappa$. The transport for the reduced Coriolis parameter is too weak in the model (square), which is a puzzle because the model and theory compare well for halocline thickness, surface salinity, and freshwater content. This appears to be due to a failure of the empirical relationship to determine the sea surface height gradient correctly.

\section{Discussion and summary}

An idealized eddy-resolving general circulation model forced by surface heat flux, uniform winds, and a parameterization of river runoff was found to reproduce a reasonable circulation of Atlantic Water, a Beaufort Gyre, exchange through Fram Strait, mean ice cover and transport, halocline depth, surface heat flux, and freshwater content. A three-layer analytic model was developed to aid in the understanding of what controls the basic characteristics of the numerical model results. The assumption that the halocline is maintained by lateral eddy fluxes from the boundary current and vertical diffusion in the interior provides the necessary conditions to obtain analytic solutions for the halocline depth, surface salinity, and freshwater content. A single nondimensional number controls most aspects of the analytic solution. Making use of an empirical relationship between sea surface height and freshwater content, the theory can also be used to predict the transport of Atlantic Water in the cyclonic boundary current. The theory compares well with a series of eddy-resolving numerical model calculations in which the vertical diffusivity, salinity and thickness of water coming off the shelf, the Coriolis parameter, and bottom topography were varied. The model halocline is maintained by lateral eddy salt fluxes of opposite sign originating from the boundaries (fresh in the upper halocline and salty in the lower halocline), with vertical diffusion in the halocline closing the salinity budget. Some level of vertical mixing in the halocline is required, but the theory and model show that realistic halocline properties and transports of Atlantic Water are obtained even for very weak mixing of magnitude consistent with observational estimates.

The ultimate driving force for the cyclonic circulation of Atlantic Water in the model is the salinity contrast between the salty Atlantic Water and the freshwater coming off the Arctic shelves. Vertical mixing is required to convert this into potential energy, which then drives the horizontal circulation. This is fundamentally different from the warm, cyclonic boundary currents driven by open ocean deep convection, as found in the Labrador Sea and Nordic seas (Spall 2004, 2011, 2012), and as would be found in the Arctic in the absence of sea ice, although boundary currents and eddy fluxes are important in both cases. The role of freshwater fluxes driving the circulation of Atlantic Water into the Arctic Basin is consistent with previous estuary models of the Arctic (e.g., Stigebrandt 1981; Rudels 1989), but these models assumed that all of the Atlantic Water was mixed into the halocline. In the present theory, the circulation of Atlantic Water in the cyclonic boundary current is stronger than the amount mixed into the freshwater layer because a much larger recirculation is required in order to support the lateral eddy fluxes that balance mixing in the interior. The exchange and mixing is regulated by the ability of eddies to transport water from the boundary current into the basin interior.

The primary role of the wind is to drive ice out of the Arctic Basin by piling it up against the North American continent (and the resulting Coriolis force advecting it through Fram Strait). This export of ice is important for balancing the net heat flux with the atmosphere. Calculations with no wind quickly develop unrealistically thick ice in the Arctic. In addition to largely insulating the surface, ice influences the circulation primarily by exerting a stress at the ocean surface. Calculations in which this ice stress forcing of the ocean is removed show a loss of the anticyclonic circulation in the western basin and an enhancement of the eddy fluxes from the boundary. The enhanced eddy fluxes indicate that the instability of the boundary current is suppressed by ice cover. Because the boundary current is more unstable, the halocline in these calculations is thinner and fresher, as expected from (10). A very similar, thin, fresh halocline is found for a calculation forced only by freshwater near the boundaries and salty water in the North Atlantic (no wind, heat flux, or ice model). This supports the conclusion that it is the freshwater forcing that is responsible for the basic circulation and halocline in the model.

The primary goal of this study was to develop a simple theoretical framework to understand the large-scale characteristics of the Arctic Ocean, primarily the circulation 
of Atlantic Water and the halocline. The key conceptual advance is to balance lateral fluxes of salt from the boundary with the vertical diffusion of salt in the basin interior, and to parameterize those salt fluxes in terms of the dominant water masses. In the present configuration, the lateral fluxes are driven by baroclinic instability of the boundary currents. It is likely that additional flux mechanisms, not considered here, are also important in the real Arctic. Interleaving is thought to contribute to the lateral spreading of Atlantic Water from the boundary current into the interior (Walsh and Carmack 2003). If a parameterization of this process were available, it could be readily built into the salt balance as in (2). It is also likely that Ekman transport associated with easterly winds along the coast of Alaska, and the anticyclonic wind stress curl in the interior of the Canada Basin, flux a significant amount of low-salinity water at the surface into the basin interior (Yang 2006; Proshutinsky et al. 2009) and could also be included in the salt budget. The eddy-driven model considered here provides an interesting starting point from which to consider additional forcing mechanisms and physical processes.

Acknowledgments. This study was supported by the National Science Foundation under Grants OCE0850416, OCE-0959381, and OCE-1232389. I would like to thank Andrey Proshutinsky and Bert Rudels for many helpful conversations about the Arctic. Any opinions, findings, and conclusions or recommendations expressed in this material are those of the author and do not necessarily reflect the views of the National Science Foundation.

\section{REFERENCES}

Aagaard, K., and E. C. Carmack, 1994: The Arctic Ocean and climate: A perspective. The Role of the Polar Oceans in Shaping the Global Climate, O. M. Johannessen, R. D. Muench, and J. E. Overland, Eds., Amer. Geophys. Union, 33-46.

Aksenov, Y. V., V. Ivanov, A. J. Nurser, S. Bacon, I. V. Polyakov, A. C. Coward, A. C. Naveira-Garabato, and A. BeszczynskaMoeller, 2011: The Arctic Circumpolar Boundary Current. J. Geophys. Res., 116, C09017, doi:10.1029/2010JC006637.

D'Asaro, E. A., 1988: Observations of small eddies in the Beaufort Sea. J. Geophys. Res., 93 (C6), 6669-6684.

Fer, I., 2009: Weak vertical diffusion allows for maintenance of cold halocline in the central Arctic. Atmos. Oceanic Sci. Lett., 2, 148-152.

Fieg, K., R. Gerdes, E. Fahrbach, A. Beszczynska, and U. Schauer, 2010: Simulation of oceanic volume transports through Fram Strait 1995-2005. Ocean Dyn., 60, 491-502.

Hibler, W. D., III, 1980: A dynamic thermodynamic sea ice model. J. Phys. Oceanogr., 9, 815-846.

Holloway, G., and Coauthors, 2007: Water properties and circulation in Arctic Ocean models. J. Geophys. Res., 112, C04S03, doi:10.1029/2006JC003642.
Hunke, E. C., and J. K. Dukowicz, 1997: An elastic-viscousplastic model for sea ice dynamics. J. Phys. Oceanogr., 27, 1849-1867.

Isachsen, P. E., 2011: Baroclinic instability and eddy tracer transport across sloping bottom topography: How well does a modified Eady model do in primitive equation simulations? Ocean Modell., 39, 183-199.

— C. Mauritzen, and H. Svendsen, 2007: Dense water formation in the Nordic seas diagnosed from sea surface buoyancy fluxes. Deep-Sea Res., 54, 22-41.

Jackett, D. R., and T. J. McDougall, 1995: Minimal adjustment of hydrographic profiles to achieve static stability. J. Atmos. Oceanic Technol., 12, 381-389.

Karcher, M., F. Kauker, R. Gerdes, E. Hunke, and J. Zhang, 2007: On the dynamics of Atlantic Water circulation in the Arctic Ocean. J. Geophys. Res., 112, C04S02, doi:10.1029/2006JC003630.

Krishfield, R. A., and D. K. Perovich, 2005: Spatial and temporal variability of oceanic heat flux to the Arctic ice pack. J. Geophys. Res., 110, C07021, doi:10.1029/2004JC002293.

Manley, T. O., and K. Hunkins, 1985: Mesoscale eddies of the Arctic Ocean. J. Geophys. Res., 90 (C3), 4911-4930.

Marnela, M., B. Rudels, M.-N. Houssais, A. Beszczynska-Möller, and P. B. Eriksson, 2012: Recirculation in the Fram Strait and transports of water in and north of the Fram Strait derived from CTD data. Ocean Sci. Discuss., 9, 3127-3190.

Marshall, J., C. Hill, L. Perelman, and A. Adcroft, 1997: Hydrostatic, quasi-hydrostatic, and non-hydrostatic ocean modeling. J. Geophys. Res., 102 (C3), 5733-5752.

Maykut, G. A., 1982: Large-scale heat exchange and ice production in the central Arctic. J. Geophys. Res., 87 (C10), 7971-7984.

Morison, J., R. Kwok, C. Peralta-Ferriz, M. Alkire, I. Rigor, R. Andersen, and M. Steele, 2012: Changing Arctic Ocean freshwater pathways. Nature, 481, 66-70, doi:10.1038/nature10705.

Muench, R. D., J. T. Gunn, T. E. Whitledge, P. Schlosser, and W. Smethie Jr., 2000: An Arctic Ocean cold core eddy. J. Geophys. Res., 105 (C10), 23 997-24006.

Pickart, R. S., T. J. Weingartner, L. J. Pratt, S. Zimmermann, and D. J. Torres, 2005: Flow of winter-transformed Pacific water into the western Arctic. Deep-Sea Res. II, 52, 3175-3198.

_- M. A. Spall, and J. T. Mathis, 2013: Dynamics of upwelling in the Alaskan Beaufort Sea and associated shelf-basin fluxes. Deep-Sea Res. I, 76, 35-51.

Plueddemann, A. J., R. Krishfield, T. Takizawa, K. Hatakeyama, and S. Honjo, 1998: Upper ocean velocities in the Beaufort Gyre. Geophys. Res. Lett., 25, 183-186.

Proshutinsky, A., and Coauthors, 2009: Beaufort Gyre freshwater reservoir: State and variability from observations. J. Geophys. Res., 114, C00A10, doi:10.1029/2008JC005104.

_ studies employing models from the Arctic Ocean Model Intercomparison Project. Oceanography, 24, 102-113, doi:10.5670/ oceanog.2011.61.

Rabe, B., U. Schauer, A. Mackensen, M. Karcher, E. Hansen, and A. Beszczynska-Möller, 2009: Freshwater components and transports in the Fram Strait recent observations and changes since the late 1990s. Ocean Sci., 5, 219-233.

Rainville, L., and P. Winsor, 2008: Mixing across the Arctic Ocean: Microstructure observations during the Beringia $2005 \mathrm{Ex}-$ pedition. Geophys. Res. Lett., 35, L08606, doi:10.1029/ 2008GL033532.

Rudels, B., 1989: The formation of Polar Surface Water, the ice export and the exchanges through Fram Strait. Prog. Oceanogr., 22, 205-248. 
__ 2012: Arctic Ocean circulation and variability_Advection and external forcing encounter constraints and local processes. Ocean Sci., 8, 261-286.

— - E. P. Jones, L. G. Anderson, and G. Kattner, 1994: On the intermediate depth waters of the Arctic Ocean. Polar Oceans and Their Role in Shaping the Global Environment, Geophys. Monogr., Vol. 85, Amer. Geophys. Union, 33-46.

_- M. Marnela, and P. Eriksson, 2008: Constraints on estimating mass, heat and freshwater transports in the Arctic Ocean: An exercise. Arctic-Subarctic Ocean Fluxes, R. R. Dickson, J. Meincke, and P. Rhines, Eds., Springer, 315-341.

Serreze, M. C., and R. G. Barry, 2005: The Arctic Climate System. Cambridge University Press, 385 pp.

Smagorinsky, J., 1963: General circulation experiments with the primitive equations: I. The basic experiment. Mon. Wea. Rev., 91, 99-164.

Spall, M. A., 2004: Boundary currents and water mass transformation in marginal seas. J. Phys. Oceanogr., 34, 1197-1213.

- 2005: Buoyancy-forced circulation in shallow marginal seas. J. Mar. Res., 63, 729-752.

_ 2010: Dynamics of downwelling in an eddy-resolving convective basin. J. Phys. Oceanogr., 40, 2341-2347.

- 2011: On the role of eddies and surface forcing in the heat transport and overturning circulation in marginal sea. J. Climate, 24, 4844-4858.

_ 2012: Influences of precipitation on water mass transformation and deep convection. J. Phys. Oceanogr., 42, 1684-1700.

- , R. S. Pickart, P. S. Fratantoni, and A. J. Plueddemann, 2008: Western Arctic shelfbreak eddies: Formation and transport. J. Phys. Oceanogr., 38, 1644-1668.

Steele, M., and W. Ermold, 2007: Steric sea level change in the Northern Seas. J. Climate, 20, 403-417.
Stigebrandt, A., 1981: A model for the thickness and salinity of the upper layer in the Arctic Ocean and the relationship between the ice thickness and some external parameters. J. Phys. Oceanogr., 11, 1407-1422.

Timmermans, M.-L., J. Toole, A. Proshutinsky, R. Krishfield, and A. Plueddemann, 2008: Eddies in the Canada Basin, Arctic Ocean, observed from ice-tethered profilers. J. Phys. Oceanogr., 38, 133-145.

Visbeck, M., M. J. Marshall, and H. Jones, 1996: Dynamics of isolated convective regions in the ocean. J. Phys. Oceanogr., 26, 1721-1734.

Walsh, D., and E. Carmack, 2003: The nested structure of Arctic thermohaline intrusions. Ocean Modell., 5, 267-289.

Woodgate, R. A., K. Aagaard, R. D. Muench, J. Gunn, G. Björk, B. Rudels, A. T. Toach, and U. Schauer, 2001: The Arctic Ocean Boundary Current along the Eurasian slope and the adjacent Lomonosov Ridge: Water mass properties, transports, and transformations from moored instruments. Deep-Sea Res., 48, 1757-1792.

, - J. Swift, and K. Falkner, 2007: Atlantic Water circulation over the Mendeleev Ridge and Chukchi Borderland from thermohaline intrusions and water mass properties. J. Geophys. Res., 112, C02005, doi:10.1029/2005JC003416.

Yang, J., 2005: The Arctic and Subarctic Ocean flux of potential vorticity and the Arctic Ocean circulation. J. Phys. Oceanogr., 35, 2387-2407.

, 2006: Seasonal variability of the Arctic Ocean Ekman transport and its role in the mixed layer heat and salt fluxes. J. Climate, 19, 5366-5387.

Zhang, J., and M. Steele, 2007: Effect of vertical mixing on the Atlantic Water layer circulation in the Arctic Ocean. J. Geophys. Res., 112, C04S04, doi:10.1029/2006JC003732. 